\title{
A Toolkit for Solving Models with a Lower Bound on Interest Rates of Stochastic Duration*
}

\author{
Bravo Working Paper \# 2020-014 \\ Gauti B. Eggertsson ${ }^{\dagger}$ \\ Sergey K. Egiev \\ Alessandro Lin \\ Josef Platzer \\ Luca Riva ${ }^{\ddagger}$
}

\begin{abstract}
This paper presents a toolkit to solve for equilibrium in economies with the effective lower bound (ELB) on the nominal interest rate in a computationally efficient way under a special assumption about the underlying shock process, a two-state Markov process with an absorbing state. We illustrate the algorithm in the canonical New Keynesian model, replicating the optimal monetary policy in Eggertsson and Woodford (2003), as well as showing how the toolkit can be used to analyse the medium-scale DSGE model developed by the Federal Reserve Bank of New York. As an application, we show how various policy rules perform relative to the optimal commitment equilibrium. A key conclusion is that previously suggested strategies - such as price level targeting and nominal GDP targeting - do not perform well when there is a small drop in the price level, as observed during the Great Recession, because they do not imply a sufficiently strong commitment to low future interest rates ("make-up strategy"). We propose two new policy rules, Cumulative Nominal GDP Targeting Rule and Symmetric Dual-Objective Targeting Rule that are more robust. Had these policies been in place in 2008, they would have reduced the output contraction by approximately 80 percent. If the Federal Reserve had followed Average Inflation Targeting - which can arguably approximate the new policy framework announced in August 2020 - the output contraction would have been roughly 25 percent smaller.
\end{abstract}

Keywords: Occasionally binding constraints; Effective Lower Bound; Regime shifts; First-order perturbation; Optimal policy; Simple policy rules; Nominal GDP target;

JEL Classification: E31, E40, E50, E60

*This paper was prepared for the Alejandro Justiniano Memorial Conference at the Federal Reserve Bank of Chicago. $\dagger$ Brown University, Department of Economics and NBER, e-mail: gauti eggertsson@brown.edu; Corresponding author. $\ddagger$ This research was partly conducted when the author was visiting Danmarks Nationalbank, the financial support and kind hospitality are gratefully acknowledged. 


\title{
A Toolkit for Solving Models with a Lower Bound on Interest Rates of Stochastic Duration*
}

\author{
Gauti B. Eggertsson ${ }^{\dagger}$ \\ Sergey K. Egiev \\ Alessandro Lin \\ Josef Platzer \\ Luca Riva
}

Brown University

October 2020

First draft: February 2020

\begin{abstract}
This paper presents a toolkit to solve for equilibrium in economies with the effective lower bound (ELB) on the nominal interest rate in a computationally efficient way under a special assumption about the underlying shock process, a two-state Markov process with an absorbing state. We illustrate the algorithm in the canonical New Keynesian model, replicating the optimal monetary policy in Eggertsson and Woodford (2003), as well as showing how the toolkit can be used to analyse the medium-scale DSGE model developed by the Federal Reserve Bank of New York. As an application, we show how various policy rules perform relative to the optimal commitment equilibrium. A key conclusion is that previously suggested strategies - such as price level targeting and nominal GDP targeting - do not perform well when there is a small drop in the price level, as observed during the Great Recession, because they do not imply a sufficiently strong commitment to low future interest rates ("make-up strategy"). We propose two new policy rules, Cumulative Nominal GDP Targeting Rule and Symmetric Dual-Objective Targeting Rule that are more robust. Had these policies been in place in 2008, they would have reduced the output contraction by approximately 80 percent. If the Federal Reserve had followed Average Inflation Targeting - which can arguably approximate the new policy framework announced in August 2020 - the output contraction would have been roughly 25 percent smaller.
\end{abstract}

Keywords: Occasionally binding constraints; Effective Lower Bound; Regime shifts; First-order perturbation; Optimal policy; Simple policy rules; Nominal GDP target;

JEL Classification: E31, E40, E50, E60

\footnotetext{
*This paper was prepared for the Alejandro Justiniano Memorial Conference at the Federal Reserve Bank of Chicago.

${ }^{\dagger}$ Brown University, Department of Economics and NBER, e-mail: gauti_eggertsson@brown.edu; Corresponding author.

¥This research was partly conducted when the author was visiting Danmarks Nationalbank; the financial support and kind hospitality are gratefully acknowledged.
} 


\section{Introduction}

The effective lower bound (ELB) on nominal interest rates has been widely studied in recent years. It is standard to analyse this problem with dynamic stochastic general equilibrium (DSGE) models, where the ELB shows up as an inequality constraint on the nominal interest rate. However, inequality constraints complicate the application of standard solution strategies, e.g. perturbation methods. These methods approximate the behaviour of a dynamical non-linear model around a point (usually, but not necessarily, via linearisation) using differentiability assumptions. Occasionally binding constraints pose a challenge for direct application of these methods.

In this paper, we present a toolkit aiming to facilitate the application of a generalised version of the solution method first used by Eggertsson and Woodford (2003), who analyse the ELB in the face of a two-state Markov process for the exogenous shocks with an absorbing state. ${ }^{1}$ We illustrate the algorithm in the canonical New Keynesian (NK) model and in the medium-scale DSGE model developed by the Federal Reserve Bank of New York (FRBNY). As an economic application, we consider various policy rules and study their performance relative to the optimal commitment equilibrium. Previously suggested policy rules - such as price level targeting and nominal GDP targeting - do not perform well when the price level does not fall by a large amount, as observed during the Great Recession, because they do not imply sufficiently strong commitment to low future interest rate ("make-up strategy"). This also applies to a policy rule we term Average Inflation Targeting, which arguably approximates the new policy regime of the Federal Reserve recently presented by Powell (2020). To solve this shortcoming, we propose two new policy rules, a Cumulative Nominal GDP Targeting Rule and a Symmetric Dual-Objective Targeting Rule that are more robust. Had either of these policy rules been in place in 2008, and believed to be credible, the model simulation suggests the Federal Reserve would have reduced the output contraction (relative to trend) by about $80-90$ percent. The comparable number for the average inflation targeting rule is 25 percent (Table 3).

Several strategies have been proposed to deal with the presence of inequality constraints in DSGE models. Eggertsson and Woodford (2003) exploit a particular structure for the exogenous disturbances: the shock process implies that the model unexpectedly moves to a "crisis state" and then reverts back to the "steady state" with a fixed probability. Once back to the steady state, it stays there forever (i.e., the steady state is an absorbing state). The idea behind the approach is intuitive: instead of treating a single dynamical system that contains both a set of equality constraints and a set of occasionally binding inequality constraints, we split the system into several parts called regimes, each of which contains equality constraints exclusively. Once cast in this form, we can apply perturbation methods, since each equation is differentiable.

An application to the ELB scenario should make this clear: we distinguish among four regimes, each of them corresponding to a different combination of the status of the inequality constraint (e.g. ELB binding or not) and the exogenous Markov disturbance (crisis or steady state). For the regimes that feature the ELB not binding, we treat the model as if the ELB was not present. In the other two regimes, when the ELB constraint is binding, the equilibrium conditions will be characterised by an equality constraint (e.g. $i_{t}=i_{t-1}=0$ ). Since all four dynamical systems are described by a set of equations, each can be solved using perturbation techniques.

The assumptions on the shock structure allow us to solve the model recursively in regimes. Starting from

\footnotetext{
${ }^{1}$ Source codes and examples are maintained at https://github.com/gautieggertsson/2-state-toolkit. Section A.2 in the Appendix presents a short user guide. Appendix B contains a number of illustrative examples.
} 
the last regime, where the ELB is not relevant, we work backwards to the period when the shock hits the system obtaining a piece-wise solution. Since outcomes in later regimes influence behaviour in earlier ones through expectations, the strategy is not based on a simple merger of separate models and sticking their solutions together.

There are two key advantages to our approach: first, its relative simplicity allows for handling of models with many state variables; second, compared to competing local solution techniques, our strategy allows for the basic stochastic structure, making it attractive for simple estimations. ${ }^{2}$ It is worth noting that there is nothing special about the interest rate constraint for using this toolkit. Any model with a constraint that is temporarily binding, can be solved using this method.

The toolkit features an algorithm that generalises the solution method in Eggertsson and Woodford (2003). In particular, it allows for the case of a regime in which the two-state Markov process is in the crisis state, but the ELB is not binding. This feature is of particular importance for our application of analysing policy rules: a common property of policy rules is that they imply an inertial response of the interest rate. An example would be a Taylor-type rule with lagged terms for the nominal interest rates. Rules of this kind often do not imply an immediate reduction of the interest rate to the ELB once the two-state Markov disturbance switches to the low state. The new feature is thus a meaningful addition and facilitates the analysis of different types of policy rules in the presence of an ELB, which is the main application in this paper.

The idea of attacking the problem by constructing a piece-wise solution is not new, nor is the idea of a toolkit applying it. In fact, Guerrieri and Iacoviello (2015), henceforth OccBin, provide a toolkit for solving dynamic models with occasionally binding constraints in a similar fashion. The main difference from OccBin is that we do not assume perfect foresight, i.e. a deterministic setting. This feature also differentiates our approach from several other strategies, such as the Extended Path algorithm. To achieve this, we rely on the specific shock structure implied by a two-state Markov process with an absorbing state. Expectations about the future path of variables are a crucial component of models related to the ELB (e.g. uncertainty whether the economy will hit the ELB and uncertain timing of lift-off), and hence allowing for uncertainty is a useful feature of the toolkit.

Adding a two-state Markov process with an absorbing state usually implies the following timing for the models analysed with the toolkit: initially, a shock hits the economy and the response of the central bank might be to immediately lower the interest rate to zero. In every period there is some probability that the disturbance reverts to its initial absorbing condition. There will often be a transition period, lasting from the point when the shock reverts to its initial level until all other variables of the model return to their steady state values. One benefit of our setup is that one can separately calibrate the expected duration of the constraint being binding from its actual, realised duration. Empirical evidence on the Great Recession, for instance the Blue Chip financial forecasts (Aspen Publishers 2008-12), suggests that market participants were expecting the ELB to bind for a much shorter time than turned out to be the case. We can account for this evidence, and can analyse several questions related to it, such as what would have been the output gains had the Federal Reserve adopted alternative policy regimes to that in place during the Financial Crisis of 2008, results that we have already noted.

The expected duration of the ELB episode is not necessarily exogenously determined simply by the transition probability of the shock: in the case of a central bank that has commitment power, the duration

\footnotetext{
${ }^{2}$ Denes, Eggertsson and Gilbukh (2013) is an example that contains a simple estimation that exploits the two-state Markov chain the toolkit solves for.
} 
of a binding ELB will typically be longer than the persistence of the disturbance in its crisis state. The periods where the inequality constraint is binding therefore does not coincide with periods where the shock is in the low state. This means that the duration at the ELB will be endogenously determined in the model, depending on the optimal decisions taken by the monetary authority, which depends, among other thing, on the realisation of the shock. This is a key challenge in solving the model discussed in detail in the body of the paper.

Our main application is monetary policy when the ELB is reached. Since the standard policy tool of affecting nominal interest rates is not available anymore, influencing expectations about their future path becomes the main lever through which the monetary authority can affect present variables. In this environment, policy rules that are able to mimic some form of commitment from the central bank are believed to perform relatively well. For example, in Eggertsson and Woodford (2003), who predict a strong deflation, rules that commit to bringing the price level back to pre-crisis levels, and to inflate in the future, are very effective. A key economic finding is that price level targeting and nominal GDP targeting do not do well if there is little fall in in inflation, as was the case during the Financial Crisis of 2008 in the U.S. The policy of price level targeting we consider is arguably equivalent to the policy of "average inflation targeting" recently adopted by the Federal Reserve when amending its policy framework in August 2020, if the average is taken over a sufficiently long period of time. We also consider an average inflation targeting regime, for which the time period averaged over is shorter. This policy provides even less stimulus at the ELB.

In addition, we propose two new rules, a Cumulative Nominal GDP Targeting Rule and a Symmetric DualObjective Targeting Rule, that imply a commitment from the central bank to make up for past deviations from target on both the price level and output. We study their performance in the standard NK model as well as in the NYFRB DSGE model and show that they generally perform better than standard rules in the literature. We show this in an environment with low inflation and small movement in the price level, as experienced during the Great Recession. Since both rules imply an aggressive reaction to past output misses, they manage to communicate that the longer the crisis, the more accommodative monetary policy will be. This in turn generates enough stimulus to prevent a large recession to start with.

Of previously proposed policy rules, the ones that perform best are the Superinertial Rule described in Rotemberg and Woodford (1999) and the Augmented Taylor Rule by Reifschneider and Williams (2000). Policy rules that do not perform as well, include Price Level and Nominal GDP Targeting, as well as Average Inflation Targeting, a result in line with Reifschneider and Wilcox (2019). The key problem of these rules, is that they do not prescribe strong enough stimulus in absence of falling inflation.

The most important advantage of the stochastic structure our toolkit embodies is that there is a clear distinction between the expected duration of the shock and the realisation of it, but the two will of course coincide under perfect foresight. This allows us to clearly show the advantage of policy commitments, such as as those exemplified by our targeting rules, relative to the optimal time-dependent policy a strategy that resembles the interventions of several central banks during the crisis of 2008. Under optimal time-dependence, the duration of the ELB is tied to calendar time. In contrast, the targeting rule we consider implies a duration at the ELB that depends upon economic conditions. We highlight that a properly chosen state-contingent policy rule vastly outperform optimal time-dependent policy, a distinction that is not as transparent in a deterministic setting.

In an additional application, we utilise our toolkit to contribute to a recent debate on the economic effects of Forward Guidance policy. We distinguish two cases: the standard theory on forward guidance creates 
additional stimulus by a fully credible announcement of keeping the interest rate at the ELB for additional periods; this is an expansionary policy. The second case is what Campbell et al. (2012) call Delphic forward guidance and Nakamura and Steinsson (2018) refer to as information effects. Here, the expected duration of the ELB episode rises as well, but this time solely due to the revelation of information leading agents to update their beliefs about economic fundamentals; this entails an economic contraction. We show that both scenarios can match the same increase in the expected duration at the ELB, but lead to vastly different economic outcomes.

The paper is structured as follows: Section 2 outlines how the solution method relates to the literature; Section 3 presents the solution algorithm; Section 4 provides a few applications in the context previously defined; Section 5 applies our toolkit to the medium-scale FRBNY DSGE model; Section 6 concludes.

\section{Related Literature}

There exists a sizeable literature on solution methods for DSGE models. ${ }^{3}$ Solution strategies can be classified into local and global methods. The former includes perturbation methods, the latter projection methods. Projection methods can handle occasionally binding constraints in a direct way, but they are associated with considerable computational burden and suffer from the curse of dimensionality.

Our approach relies on perturbation. Generally, provided the system in question is well behaved, perturbation methods can handle large models with many state variables and provide a high quality of approximation. However, in the presence of occasionally binding constraints differentiability does not hold everywhere.

Several attempts have been made to address this issue: our approach is a re-work and extension of the algorithm proposed in Eggertsson and Woodford (2003) that solves a NK model with a ELB in a fully stochastic setting. Jung, Teranishi and Watanabe (2005) is another early strategy based on a piece-wise solution, but in a deterministic environment. The paper closest in spirit to ours is Guerrieri and Iacoviello (2015), already mentioned in the introduction. Occbin solves deterministic dynamic models with occasionally binding constraints by piece-wise first-order perturbation. It can handle an AR(1) shock structure, independent shocks, several alternations between slack and binding modes in one simulation. However, it assumes perfect foresight. From this discussion it should be clear that our toolkit is complementary to OccBin. Each is tailored to a particular set of questions. Both have in common that they are easily implementable.

Doubts have been raised whether linearisation offers a good approximation to the fully non-linear system dynamics in the presence of the ELB, see for example Boneva, Braun and Waki (2016). Eggertsson and Singh (2019) look at the non-linear version of Eggertsson and Woodford (2003) and find that the approximation error is modest even for large disturbances, provided the approximated solution is parameterized to match the same empirical evidence and the non-linear solution. They also comment on poor approximation results that have been mentioned in relation to Rotemberg pricing, ${ }^{4}$ a finding they ultimately trace back to how the cost of price changes shows up in the resource constraint of the model, rather than errors introduced by linearisation.

One way to account for the ELB is to replace the inequality constraint with news shocks: ones that are realised some time before they actually enter equations of the model. Laséen and Svensson (2011)

\footnotetext{
${ }^{3}$ For an overview we refer to the recent handbook chapter by Fernández-Villaverde, Rubio-Ramírez and Schorfheide (2016).

${ }^{4}$ This point was also made in Miao and Ngo (2019).
} 
and Holden and Paetz (2012) develop this point: they use such disturbances to transform a non-linear constraint into "as if" linear models. The approach is able to handle higher order approximations as well as uncertainty. Holden (2016) offers a Dynare toolbox for the easy implementation of the procedure, DynareOCB, providing reliable accuracy with sufficient speed.

Another local method of solving large systems within reasonable time is the Extended Path algorithm (EP), proposed by Fair and Taylor (1983) and applied to a model with a ELB by Adjemian and Juillard (2011). This method sets a terminal date when the solution trajectory is assumed to be sufficiently close to the steady state. The EP algorithm is solved under perfect foresight: at each point in time, all future shocks are assumed to be equal to their expected values of zero. Adjemian and Juillard (2013) note that ignoring Jensen's inequality under an EP approach leads to a sizeable approximation error in models with occasionally-binding constraints. The authors extend EP to a Stochastic Extended Path algorithm that is more suitable for a setting with non-linear constraints. It is somewhat of a middle ground between perfect foresight and a fully stochastic setting: for some finite number of periods ahead, the setting is stochastic (e.g. the expectation is explicitly approximated via quadrature integration) while after that period all disturbances are assumed to be zero.

Another strategy is to replace the inequality constraint by a smooth penalty function, thereby eliminating the inequality constraints from the model (this is also referred to as barrier method). The idea is to penalise the agents' utility in cases where the inequality constraint is violated. This method is used in outlined in Judd (1998) and put to use in Preston and Roca (2007) and Kim, Kollmann and Kim (2010), among others. In the centext of the ELB it is first applied in Rotemberg and Woodford (1997). ${ }^{5}$

The advantage of the approaches discussed so far is that they can manage medium- to large-sized models in reasonable time. Global solution methods can account for non-linearities and deliver solutions with high precision, but suffer from the curse of dimensionality. Improvements in computation power and methods, make this more direct approach, however, increasingly more attractive and applicable. ${ }^{6}$

Some papers using projection methods to analyse the ELB should also be mentioned here: Adam and Billi (2006) and Nakov (2008) work with the linearised system of equations of standard NK models, and the ELB is the only source of non-linearity. Fernández-Villaverde, Rubio-Ramírez and Schorfheide (2016) solve the fully non-linear model and highlight the benefits of this approach.

It is worth highlighting an important limitation of the solution method applied in this paper, that makes it less appropriate to analyse some questions. Due to the that the shock that generates the ELB returns to an absorbing steady state, our method is not suitable to address questions related to repeated episodes of the ELB. For example, if one wants to address how anticipation future ELB episodes matter for policy under normal circumstances, the method developed here is not useful, absent further extensions. Global methods, in contrast, are well suitable for this class of questions.

Given the numerous and powerful alternatives available, we do not claim superiority to any of the presented methods. Which approach suits best for a particular problem at hand will have to be evaluated on an individual basis. Our method has the advantage of tractability, simplicity, fast implementation, and the flexibility to account for a particular kind of uncertainty that has been popular in the literature.

In an application of the toolkit, we analyse optimal policy rules in economies at risk of hitting the ELB.

\footnotetext{
${ }^{5}$ An application to the ELB is also discussed in Woodford (2003), Chapter 6, Section 4.2.

${ }^{6}$ Maliar and Maliar (2015) is a recent attempt to ameliorate the curse of dimensionality when using projection methods: the key to this result is to repeatedly choose the grid on which the projection method operates in a smart way, using a stochastic simulations approach. Gust et al. (2017) use this method to solve a medium-scale DSGE model with an occasionally-binding ZLB constraint and use the methodology to estimate the model using Bayesian methods.
} 
There is a vast literature analysing optimal rules. Recent contributions include Kiley and Roberts (2017), Mertens and Williams (2019a) and Mertens and Williams (2019b). Nakov (2008) is an earlier paper looking at optimal rules at the ELB. Our analysis highlights the implications of a stable price level for rules like price level targeting and nominal GDP targeting, and proposes rules that are robust to such environments.

\section{A Piece-wise Linear Solution to Rational Expectations Models with Inequality Constraints}

\subsection{Basic Idea}

In this section we outline our approach in applying perturbation methods to models with inequality constraints. ${ }^{7}$ Technically, the use of the implicit function theorem (IFT) on which perturbation methods rely requires the function approximated to be smooth. Inequality constraints introduce a kink in the model at the point where the inequality constraint becomes binding. On a more intuitive level, once the inequality constraint becomes binding (or slack, depending on the point of approximation), local approximation via IFT becomes inaccurate.

The basic idea of our approach is to circumvent this problem by the following: we split the model into several parts, called regimes, depending on which set of equations applies. This strategy decomposes the inequality constraints that characterises the model in general into several equality constraints that characterise each regime separately. This turns one system with occasionally binding constraints into several interlinked systems. Critically though, it does not simply amount to transforming the problem into independent dynamical linear systems: optimal decision-making in the current regime takes into account uncertainty as to what regime will govern future dynamics of the model, thus linking the dynamics of one regime to the next.

We assume the fundamental disturbance $\epsilon_{t} \in\left\{\epsilon_{L}, \epsilon_{H}\right\}$ hitting the system to be characterised by a twostate Markov process with an absorbing state, i.e. $P\left(\epsilon_{t+1}=\epsilon_{L} \mid \epsilon_{t}=\epsilon_{L}\right)=\mu$ and $P\left(\epsilon_{t+1}=\epsilon_{H} \mid \epsilon_{t}=\epsilon_{H}\right)=$ 1. ${ }^{8}$ This assumption buys a lot: this shock structure allows for the decomposition of a single dynamical system into several regimes. ${ }^{9}$ In the applications we consider in this paper, the regimes are:

0. $0<t<\tilde{T}$ : the shock is in the low state, $\epsilon_{t}=\epsilon_{L}$ and the ELB is not yet binding; ${ }^{10}$

1. $\tilde{T} \leq t<\tau$ : the shock is in the low state, $\epsilon_{t}=\epsilon_{L}$, and the ELB is binding;

2. $\tau \leq t<\tau+k_{\tau}$ : the shock has returned to the high, absorbing state, $\epsilon_{t}=\epsilon_{H}$ but the ELB is still binding;

3. $\tau+k_{\tau} \leq t$ : the shock remains in the absorbing state, $\epsilon_{t}=\epsilon_{H}$, and the ELB is not binding.

\footnotetext{
${ }^{7}$ See Fernández-Villaverde, Rubio-Ramírez and Schorfheide (2016) for an overview on solution methods for macroeconomic models, including perturbation methods. Schmitt-Grohé and Uribe (2009) and Judd (1998) are excellent sources for in depth treatment of perturbation methods.

${ }^{8}$ The exogenous disturbance $\epsilon_{t}$ needs not to be a scalar. As long as the shocks are perfectly correlated, one should think of $\epsilon_{t}$ as a vector of perfectly correlated innovations.

${ }^{9}$ An example of this in the context of the ELB would be optimal policy by the central bank under commitment. Here we can split the problem into three regimes, one where the shock is over and the ELB is slack, one where the shock is over but the ELB binds, and one where the shock is on an the ELB binds. Note that not every problem needs to have three (or four) regimes: the problem of the central bank under discretion (without endogenous state variables) will typically only have two regimes.

${ }^{10}$ This regime generalises the solution method in Eggertsson and Woodford (2003) to allow for very sluggish policy rules. Notice that $\tilde{T}$ can be 1 , meaning that regime 0 never starts. This is the case, for example, of a fully forward-looking economy such as the standard NK model with a policy rule that has no lagged term.
} 
At time $t=1$ a realisation of the shock in the low state hits the system, $\epsilon_{1}=\epsilon_{L}$. In period $t=\tau$ the disturbance reverts to the high, absorbing state and stays there forever. Note that for each possible $\tau$, the solution proposed above prescribes $k_{\tau}$ additional periods in which the ELB is binding.

As for the inequality constraint, there are a few switching points: first, the inequality constraint is binding starting from some point in time $\tilde{T}$; this is the switching time from regime 0 to regime $1 .{ }^{11}$ Note that from the agents' perspective $\tilde{T}$ is known and deterministic. Second, when the shock has reverted to its absorbing state at time $\tau$ the inequality constraint could still be binding. This situation constitutes a separate regime and the switching time is stochastic by nature as it is governed by the Markov process. $\tau$ is the switching time from regime 0 or 1 to regime 2 . The duration of regime 2 is denoted by $k_{\tau}$, and might depend on the duration of the preceding regimes. Finally, $\tau+k_{\tau}$ represents the time when the economy switches from regime 2 to regime 3 , where the shock is in its absorbing state and the constraint does not bind anymore; regime 3 governs the dynamics thereafter. ${ }^{12}$

To take into account the expectations channel that interlinks the regimes, we solve the problem backwards, starting with regime 3 . Note that since we assume an absorbing state for the exogenous shock, the system is deterministic in regimes 2 and 3 . It is in regimes 0 and 1 , where expectations about future realisations of the shock affect the current behaviour, that the stochastic setting comes into play.

\subsection{General Formulation}

To introduce technical notation, many macroeconomic models can be formulated in the following form:

$$
\mathbb{E}_{t} \tilde{f}\left(\tilde{\zeta}_{t+1}, \tilde{\zeta}_{t}, \tilde{\epsilon}_{t}\right) \leq 0
$$

where $\tilde{\xi}_{t}$ is a vector of endogenous variables and $\tilde{\epsilon}_{t}$ is a (vector) shock following a two-state Markov process with an absorbing state. ${ }^{13}$ The disturbance switches back to the absorbing state with probability one at a (deterministic) time, $\tau_{\max }{ }^{14} \mathbb{E}_{t}$ is the mathematical operator for expectation conditional on information available at time $t$ and $\tilde{f}(\cdot, \cdot, \cdot)$ is a differentiable function. Typically, $\tilde{f}$ contains structural equations and/or necessary first order conditions of an optimisation problem arising in a microfounded economic model. The inequality sign in (1) accounts for the presence of inequality constraints. ${ }^{15}$ For the sake of convenience, we transform the notation in (1) as follows:

$$
\mathbb{E}_{t} f^{*}\left(\xi_{t+1}^{*}, \xi_{t}^{*}\right) \leq 0
$$

where $\xi_{t}^{*}=\left[\tilde{\xi}_{t}, \tilde{\epsilon}_{t-1}\right]^{\prime}=\left[Z_{t}^{*}, S_{t-1}^{*}, \tilde{\epsilon}_{t-1}\right]^{\prime}$ is a vector of $N_{Y}^{*}=\left(N_{Z}+N_{S}+N_{\epsilon}\right)$ elements, of which $N_{Z}$ nonpredetermined (or jump) variables $Z_{t}^{*}, N_{S}$ predetermined variables $S_{t-1}^{*}$, and $N_{\epsilon}$ exogenous disturbances $\tilde{\epsilon}_{t-1}$.

In order to deal with the inequality constraints, we propose to split the problem into several regimes. In each regime the system of equations can take a different form, so we denote each resulting system by

\footnotetext{
${ }^{11}$ Notice that the toolkit allows for $\tilde{T}$ to be "large enough", meaning that regime 1 never starts. This generalises the use of the toolkit for shocks that are enough small to not trigger the inequality constraint to bind.

${ }^{12}$ The toolkit in its current version does not allow to switch from a higher regime back to a lower regime. This means we do not allow to move from regime 1 to regime 0 , or from regime 3 to regime 2. Some models could require such a feature for a solution to be found, e.g. in models implying a lot of inertia. We never encountered such a case when working with the toolkit.

${ }^{13}$ This notation requires that exogenous variables appear in present values only.

${ }^{14}$ Note that $\tau_{\max }$ can be set so that the period at which the shock reverts to its high state is arbitrarily far in the future.

${ }^{15}$ The full set of first order conditions usually also includes transversality conditions, No-Ponzi scheme conditions and initial conditions. For brevity's sake we do not explicitly formulate them. Moreover, note that this formulation is general enough to include higher order difference equations, since they can be easily transformed into first order difference equations by redefining $\tilde{\xi}$.
} 
another subscript. Importantly, the inequality constraints are either slack or binding, so that we write a system of equations instead of inequalities. We denote each system of equations by the following:

$$
\mathbb{E}_{t} f_{i}^{*}\left(\xi_{t+1}^{*}, \xi_{t}^{*}\right)=0
$$

where $i \in\{0,1,2,3\}$ indicates the regime.

Next, we approximate the non-linear systems of equations in (3) to the first order around a specific point. Usually, we approximate around the deterministic steady state $\bar{\xi}$ of some "baseline regime" $\tilde{i}$ that fulfils:

$$
f_{\tilde{i}}^{*}(\bar{\xi}, \bar{\xi})=0
$$

We can choose to linearise around an equilibrium point of any regime, and the particular choice will depend on the application. We can write the resulting linear system of equations in the following general form:

$$
A^{i} \mathbb{E}_{t} \xi_{t+1}=B^{i} \xi_{t}
$$

where $A^{i}, B^{i}$ are $N_{Y} \times N_{Y}$ coefficient matrices and $\xi_{t}=\left[Z_{t}, S_{t-1}, \epsilon_{t-1}, C_{t}\right]^{\prime}=\left[Z_{t}, P_{t-1}\right]^{\prime}$ is a $N_{Y}=$ $\left(N_{Y}^{*}+1\right) \times 1$ vector. $^{16}$ The variables $\xi_{t}, Z_{T}, S_{t}, \epsilon_{t}, P_{t}$ are now written without star: this due to the process of linearisation, where the variables are often transformed, e.g. to log-deviation from steady state. The term $C_{t}$ accounts for binding inequality constraint. ${ }^{17}$

The solution path to small perturbations that is derived from the linearised system in (5) will be exact only up to a residual of order $\mathcal{O}\left(\|\epsilon, \bar{\delta}\|^{2}\right)$. The $\mathcal{O}($.$) term is the remainder appearing in the first-order$ Taylor-series approximation. In addition, $\epsilon$ in the big-O expression refers to the perturbation of the shock variable and $\bar{\delta}$ takes account of the fact that the equilibrium in regimes other than the baseline might not coincide with the point we linearise around. This amounts to another "perturbation" that brings us off the point we approximate around. In our examples we will usually have $\bar{\delta}=\frac{i-\bar{i}}{1+i}$, with $\bar{i}$ being the non-stochastic steady-state interest rate. Then we will have $\bar{\delta} \neq 0$ if $i=0$, which is the case in regimes 1 and 2.

As noted in Eggertsson and Woodford (2003), as well as in Woodford (2003) p.383 ff., perturbation theory provides accurate linearised solutions only for shocks that are small enough, i.e. both $\epsilon$ and $\delta$ small. We now briefly discuss this assumption: Eggertsson and Woodford (2003) show that we can make $\bar{\delta}$ arbitrarily small by assuming that there is interest paid on base money. In our application, $\bar{\delta}$ is close to realistic values (e.g. a drop of the interest rate from 3 percent to 0 ), and we hope (without verifying) that our linear approximation will be accurate. Eggertsson and Singh (2019) compare the fully non-linear version of a standard NK model with a binding ELB to the log-linearised one, and find that they behave similarly for reasonable values of disturbances, including ours.

The system in (5) has a familiar form and we can therefore apply standard rational-expectations solution methods. All regimes except the last will have a finite duration. Blanchard and Kahn (1980) present the conditions under which a system of infinite horizon like (5) has a unique bounded solution. The regimes

\footnotetext{
${ }^{16}$ The vector $P_{t}$ contains all predetermined variables, which include past exogenous shocks as well as constants.

${ }^{17}$ When the constraint is not binding we typically have $C_{t}=0$. To give a concrete example, consider the zero lower bound and the nominal rate $i_{t}$. We can define $\hat{i}_{t}=\frac{i_{t}-\bar{i}}{1+\bar{i}}$. When the zero bound is binding, we have $i_{t}=0$ and $\hat{i}_{t}=-\frac{\bar{i}}{1+\bar{i}}$. This is an example of a constant term.
} 
before the last will have a finite terminal date and can be solved recursively. Solutions will take the form:

$$
\begin{aligned}
& P_{t}=G_{t}^{i} P_{t-1} \\
& Z_{t}=D_{t}^{i} P_{t}
\end{aligned}
$$

where $G_{t}^{i}$ and $D_{t}^{i}$ are transition matrices. We see that time $t$ variables will be a linear combination of pre-determined variables, shocks and constants. Once we find all transition matrices an initial condition for the predetermined variables $P_{0}$ allows us to compute the evolution of the dynamical system.

\subsection{The Solution Algorithm}

After this general outline of our approach, we want to show the way to derive the transition matrices of every regime. Since transition matrices of earlier regimes depend on later ones, we solve the problem recursively. We will first take the length of each regime as given and then discuss how to determine a vector $k$ and the time $\tilde{T}$. The former contains the length of regime 2 for each realisation of the shock path. We will refer to those realisations as contingencies.

\subsubsection{Finding the transition matrices in all four regimes given $k$ and $\tilde{T}$}

Here we describe the construction of matrices $G_{t}^{i}$ and $D_{t}^{i}$ for each regime. We will rename the matrices according to the following notation, so that they correspond to the state they are in.

\begin{tabular}{r|ccccccccccc} 
Period $t$ & $t<\tilde{T}$ & $\ldots$ & $\tilde{T}$ & $\ldots$ & $t<\tau$ & $\ldots$ & $\tau$ & $\ldots$ & $\tau \leq t<\tau+k_{\tau}$ & $\ldots$ & $t \geq \tau+k_{\tau}$ \\
\hline$D_{t}$ & $D^{0, t}$ & $\ldots$ & $D^{1, \tilde{T}}$ & $\ldots$ & $D^{1, t}$ & $\ldots$ & $D^{2, k_{\tau}}$ & $\ldots$ & $D^{2, j}$ & $\ldots$ & $D^{3}$ \\
$G_{t}$ & $G^{0, t}$ & $\ldots$ & $G^{1, \tilde{T}}$ & $\ldots$ & $G^{1, t}$ & $\ldots$ & $G^{2, k_{\tau}}$ & $\ldots$ & $G^{2, j}$ & $\ldots$ & $G^{3}$
\end{tabular}

where $j=k_{\tau}-(t-\tau)$ denotes how many periods are left until the ELB is no longer binding.

Solution for regime 3: $t \geq \tau+k_{\tau}$. The system can be written in the following form:

$$
A^{3} \mathbb{E}_{t}\left[\begin{array}{c}
Z_{t+1} \\
P_{t}
\end{array}\right]=B^{3}\left[\begin{array}{c}
Z_{t} \\
P_{t-1}
\end{array}\right]
$$

A system of this form can be solved by the method outlined in Blanchard and Kahn (1980) as well as in King and Watson (1998).

The solution takes the form:

$$
\begin{aligned}
& P_{t}=G^{3} P_{t-1} \\
& Z_{t}=D^{3} P_{t-1} .
\end{aligned}
$$

Superscript 3 denotes the regime, and no subscripts are present because $D^{3}$ and $G^{3}$ do not depend on time.

Solution for regime 2: $\tau \leq t<\tau+k_{\tau}$. As in the previous case, the system can be written as: 


$$
\begin{aligned}
A^{2} \mathbb{E}_{t}\left[\begin{array}{c}
Z_{t+1} \\
P_{t}
\end{array}\right] & =B^{2}\left[\begin{array}{c}
Z_{t} \\
P_{t-1}
\end{array}\right] \\
{\left[\begin{array}{ll}
A_{1}^{2} & A_{2}^{2} \\
A_{3}^{2} & A_{4}^{2}
\end{array}\right]\left[\begin{array}{c}
\mathbb{E}_{t} Z_{t+1} \\
P_{t}
\end{array}\right] } & =\left[\begin{array}{ll}
B_{1}^{2} & B_{2}^{2} \\
B_{3}^{2} & B_{4}^{2}
\end{array}\right]\left[\begin{array}{c}
Z_{t} \\
P_{t-1}
\end{array}\right]
\end{aligned}
$$

and we want to find a solution of the form:

$$
\begin{aligned}
& P_{t}=G^{2, j} P_{t-1} \\
& Z_{t}=D^{2, j} P_{t-1} .
\end{aligned}
$$

We show how to derive those matrices in the following Lemma 1.

Lemma 1. Let $\tilde{A}$ be the reduced row echelon form of $\tilde{B}$, where

$$
\tilde{A}=\left[\begin{array}{llll}
I & 0 & -C_{1} & -C_{2} \\
0 & I & -C_{3} & -C_{4}
\end{array}\right] \text { and } \tilde{B}=\left[\begin{array}{llll}
A_{2}^{2} & -B_{1}^{2} & -B_{2}^{2} & A_{1}^{2} \\
A_{4}^{2} & -B_{3}^{2} & -B_{4}^{2} & A_{3}^{2}
\end{array}\right] \text {. }
$$

The solution in regime 2 will be: ${ }^{18}$

$$
\begin{aligned}
& G^{2, j}=\left[I-C_{2} D^{2, j-1}\right]^{-1} C_{1} \\
& D^{2, j}=C_{3}+C_{4} D^{2, j-1} G^{2, j} .
\end{aligned}
$$

Also, it will hold $D^{2,0}=D^{3}$, and $G^{2,0}=G^{3}$.

Proof. See Appendix A.1.

Solution for regime 1: $t<\tau$. Similarly to regime 2 , we can write the solution into the form

$$
\left[\begin{array}{cc}
A_{1}^{1} & A_{2}^{1} \\
A_{3}^{1} & A_{4}^{1}
\end{array}\right]\left[\begin{array}{c}
\mathbb{E}_{t} Z_{t+1} \\
P_{t}
\end{array}\right]=\left[\begin{array}{ll}
B_{1}^{1} & B_{2}^{1} \\
B_{3}^{1} & B_{4}^{1}
\end{array}\right]\left[\begin{array}{c}
Z_{t} \\
P_{t-1}
\end{array}\right]
$$

Note that the transition matrices will now be time varying. This is because in regime 1 the expectations at time $t$ depend on $k_{t+1}$, since $E_{t} Z_{t+1}=\mu Z_{t+1 \mid \epsilon_{t+1}=\epsilon_{L}}+(1-\mu) Z_{t+1 \mid \epsilon_{t+1}=\epsilon_{H}}=\mu D_{t+1}^{1} P_{t}+(1-$ $\mu) D^{2, k_{t+1}} P_{t} \equiv \check{D}_{t}^{1} P_{t}$. Recall that with probability $\mu$ the shock will stay in the low state, while with probability $1-\mu$ the shock will switch back to the high state and the coefficient matrix $D$ will be calculated according to the next regime.

Let $\tilde{C}_{t}$ be the row reduced echelon form of $\tilde{D}_{t}$, where:

$$
\tilde{C}_{t}=\left[\begin{array}{llll}
I & 0 & -C_{t, 1} & -C_{t, 2} \\
0 & I & -C_{t, 3} & -C_{t, 4}
\end{array}\right] \quad \text { and } \quad \tilde{D}_{t}=\left[\begin{array}{llll}
A_{t, 2} & -B_{t, 1} & -B_{t, 2} & A_{t, 1} \\
A_{t, 4} & -B_{t, 3} & -B_{t, 4} & A_{t, 3}
\end{array}\right] .
$$

\footnotetext{
${ }^{18}$ We make use of the deterministic nature of regimes 2 and 3 to ignore the expectation term.
} 
Then, we can rewrite the system to be:

$$
\left[\begin{array}{c}
P_{t} \\
Z_{t}
\end{array}\right]=\left[\begin{array}{ll}
C_{t, 1} & C_{t, 2} \\
C_{t, 3} & C_{t, 4}
\end{array}\right]\left[\begin{array}{c}
P_{t-1} \\
\mathbb{E}_{t} Z_{t+1}
\end{array}\right]=\left[\begin{array}{ll}
C_{t, 1} & C_{t, 2} \\
C_{t, 3} & C_{t, 4}
\end{array}\right]\left[\begin{array}{c}
P_{t-1} \\
\check{D}_{t}^{1} P_{t}
\end{array}\right] .
$$

Once again, we want to find a solution of the form:

$$
\begin{aligned}
& P_{t}=G^{1, t} P_{t-1} \\
& Z_{t}=D^{1, t} P_{t-1} .
\end{aligned}
$$

To solve for these matrices we assume that at some time $\tau_{\max }$ the probability of the shock returning to its absorbing state (given that this did not happen at time $\tau_{\max }-1$ ) is no longer $1-\mu$, but 1 . This allows us to use the same solution strategy as in regime 2 to obtain:

$$
\begin{aligned}
& G^{1, \tau_{\max }-1}=\left[I-C_{2} D^{2, k_{\tau_{\max }}}\right]^{-1} C_{\tau_{\max }, 1} \\
& D^{1, \tau_{\max }-1}=C_{3}+C_{4} D^{2, k_{\tau_{\max }}} G^{1, \tau_{\max }-1} .
\end{aligned}
$$

We can apply this methodology recursively for $t<\tau_{\max }-1$ :

$$
\begin{aligned}
G^{1, t} & =\left[I-C_{t, 2} \check{D}_{t}^{1}\right]^{-1} C_{t, 1} \\
D^{1, t} & =C_{t, 3}+C_{t, 4} \check{D}_{t}^{1} G^{1, t} .
\end{aligned}
$$

Solution for regime $0: t<\tilde{T}$. The solution for regime 0 follows the same procedure to the one for regime 1. The only difference is that the matrices $A$ and $B$ differ from those in regime 1 . Regime 0 holds until time $t=\tilde{T}$. The transition matrices in regime 0 will have the form:

$$
\begin{aligned}
& G^{0, t}=\left[I-C_{t, 2} \check{D}_{t}^{0}\right]^{-1} C_{t, 1} \\
& D^{0, t}=C_{t, 3}+C_{t, 4} \check{D}_{t}^{0} G^{0, t}
\end{aligned}
$$

So far we have considered the vector $k$ (the duration of regime 2 for each and every $\tau$ ) and the scalar $\tilde{T}$ (the period in which regime 1 starts holding) to be known by the agents of the economy. The next Sections explain the algorithm we use to find them.

\subsubsection{Finding $k$ given $\tilde{T}$}

The algorithm to find $k$ for a given $\tilde{T}$ is straightforward: we start from a vector of zeros, namely that regime 2 is never believed to hold, under any contingency. We then use the transition matrices found as described in the previous section and trace the evolution of all variables, including the one constrained with inequality (e.g. the nominal interest rate). Starting from the first contingency, we then check whether the inequality constraint is violated in the first period of regime 3. In case it is not violated, we move forward to the next contingency until we encounter a contingency for which, according to the transition matrices, the inequality is violated in the first period of regime 3 . Whenever we find such a contingency, we update $k$ by adding one unit to the duration of regime 2 under such contingency.

In the interest of saving computing power, it is possible to assume that there is an increasing relationship 
between the contingency and the length of regime 2. Such an assumption is harmless in some models but it is still to be shown that the results are not affected in general. If one wants to verify that a given $k$ does indeed imply a solution to the dynamic system, it is possible to check that the necessary condition on the variable whose constraint is potentially binding is not violated. ${ }^{19}$ After having updated $k$, we proceed as explained in the previous sections by calculating a new set of transition matrices and then we follow the algorithm outlined above to check if there is some contingency for which the inequality is violated in the first period of regime $3 .^{20}$

\subsubsection{Finding $\tilde{T}$}

The algorithm to find $\tilde{T}$ is intuitive. For a given $\tilde{T}$, say $T$ (which is initialised at 1 ), we take two steps to check whether it is the solution: first, for $\tilde{T}=T$, meaning that regime 1 starts at time $T$, we check that the inequality constraint is not violated at $t=T-1$; second, we impose $\tilde{T}=T+1$, assuming that regime 1 starts at $T+1$. We find the corresponding $k$, simulate the economy forward, and finally check whether the inequality constraint is violated for $t=T$. If the inequality constraint is indeed violated, then regime 1 should start at $t=T+1-1=T$ and we conclude that $\tilde{T}=T$. If the inequality constraint is not violated for $t=T$, this implies that regime 0 is correctly imposed in $t=T+1$. In such case we continue iterating by increasing $T$ by one.

\section{Applications}

As an application we revisit Eggertsson and Woodford (2003), henceforth EW2003, and analyse the optimal monetary policy at the ELB in the standard NK model. We then ask what kind of policy rule can implement it. Our key finding is that EW2003 suggests a simplified price level targeting rule which performs poorly in replicating the optimal commitment in numerical experiments where the price level does not drop much at the ELB. We consider this scenario because of its similarity to the Great Recession in the United States, and because it stands in stark contrast with the experiment considered in EW2003. We also show that popular policy proposals such as nominal GDP targeting do relatively poorly in simulations in which there is not a significant fall in the price level at the ELB. We explain the logic of this result and suggest new alternative policy rules that do better. Finally, we confirm that the insights from the numerical experiments in the standard two-equation NK model extends to a medium-scale quantitative model, such as the one used by the Federal Reserve Bank of New York.

\subsection{The Optimal Policy Commitment in Eggertsson and Woodford (2003)}

EW2003 presents the standard two-equation NK model and analyses the optimal monetary policy under commitment (OCP) taking account of the ELB. The policy can be represented by the following set of

\footnotetext{
${ }^{19}$ This situation arises for example when a Taylor rule does prescribe a negative nominal interest rate, or - as in Eggertsson and Woodford (2003) - when the Lagrange multiplier is correctly non-negative.

${ }^{20}$ Following this procedure, it is possible to find a $k$ that solves the dynamic system with binding constraints. The existence of a $k$ does not imply its uniqueness. However, we never found multiple solutions to the same problem when applying our solution method.
} 

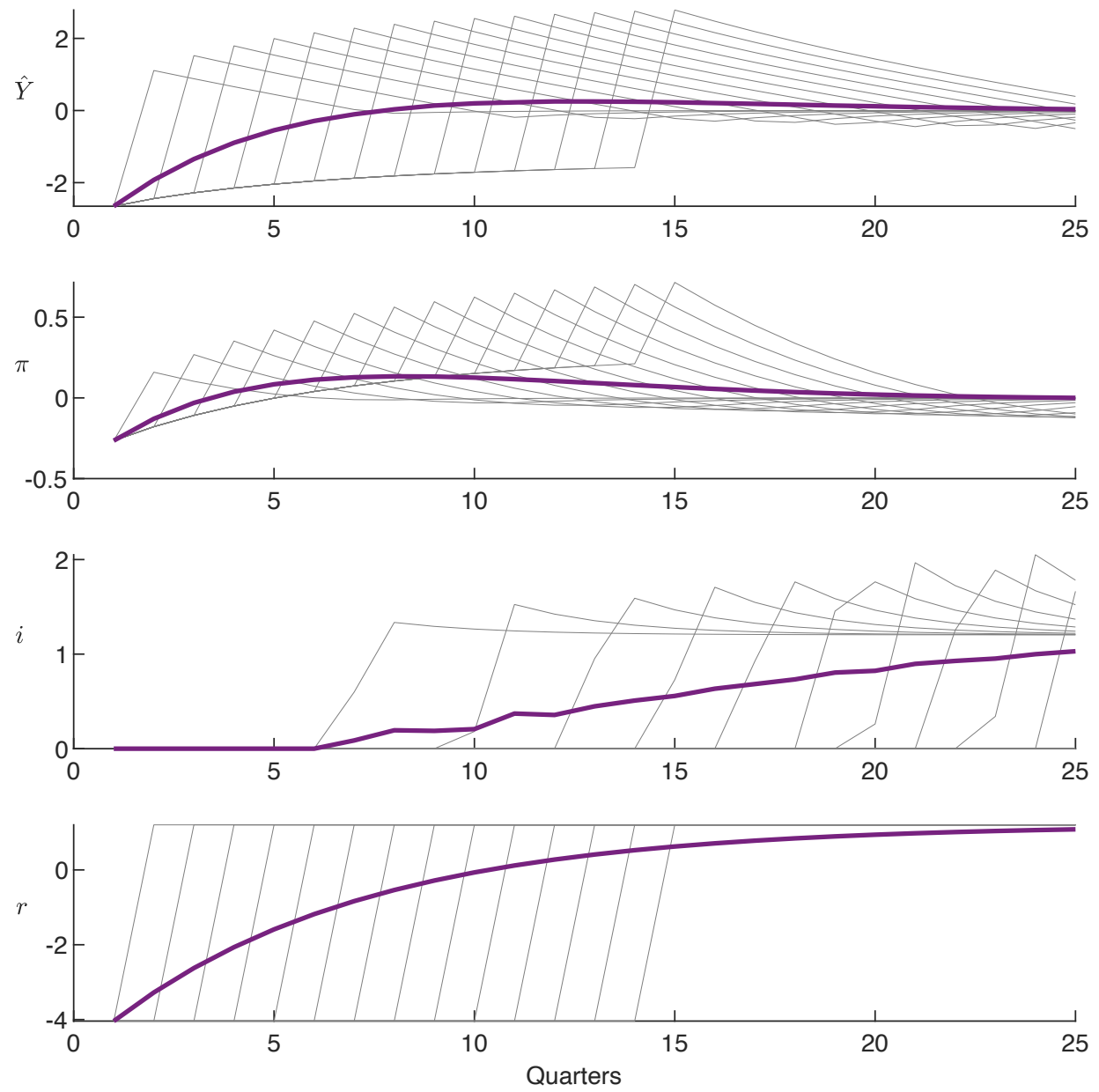

Figure 1: Optimal Commitment Policy as in Eggertsson and Woodford (2003). Coloured lines are the impulse response for output $(\hat{Y})$, inflation $(\pi)$, the nominal interest rate $(i)$, and natural rate $\left(r^{n}\right)$, grey lines represent the evolution for single contingencies (from 2 to 15). The vertical axes report deviations from steady state, in percentage points (annualised). The vertical axis for the interest rate reports annualised percentage points. 
equations: ${ }^{21}$

$$
\begin{aligned}
\hat{Y}_{t} & =\mathbb{E}_{t} \hat{Y}_{t+1}-\sigma\left(i_{t}-\mathbb{E}_{t} \hat{\pi}_{t+1}-r_{t}^{n}\right) \\
\hat{\pi}_{t} & =\kappa \hat{Y}_{t}+\beta \mathbb{E}_{t} \hat{\pi}_{t+1} \\
0 & =\hat{\pi}_{t}+\phi_{2 t}-\phi_{2 t-1}-\frac{1}{\beta} \sigma \phi_{1 t-1} \\
0 & =\lambda \hat{Y}_{t}+\phi_{1 t}-\frac{1}{\beta} \phi_{1 t-1}-\kappa \phi_{2 t} \\
\phi_{1 t} & \geq 0 \\
i_{t} & \geq 0 \\
\phi_{1 t} i_{t} & =0
\end{aligned}
$$

where $\hat{Y}_{t}$ is output in deviation from steady state, $\hat{\pi}_{t}$ is inflation, $i_{t}$ is the nominal interest rate, $\phi_{1 t}$ and $\phi_{2 t}$ are Lagrange multipliers, and $r_{t}^{n}$ is an exogenous disturbance - the natural rate of interest - that follows a two-state Markov process. Specifically, there is an unexpected reduction in the natural rate of interest in period 1 so that $r_{1}^{n}=r_{L}^{n}<0$, and

$$
r_{t>1}^{n}=\left\{\begin{array}{lll}
r_{L}^{n} & \text { w.p. } \mu & \text { if } r_{t-1}^{n}=r_{L} \\
r_{H}^{n} & \text { w.p. } 1-\mu & \text { if } r_{t-1}^{n}=r_{L} \\
r_{H}^{n} & & \text { if } r_{t-1}^{n}=r_{H}
\end{array}\right.
$$

The toolkit simulates the economy described above and produces the outputs as shown in Figure 1, which replicates the results in EW2003. We outline the steps required for coding the simulation in Appendix A.2. Each of the light grey lines represents a contingency, i.e. a specific realisation of the Markov process. Note that the time period at which the exogenous disturbance switches to its absorbing state is sufficient to characterise the specific realisation. For this reason, one can refer to a contingency as the period at which the exogenous shock is back to its steady state. For example, the third grey line from the left for inflation, output and interest rates corresponds to the case in which the natural rate of interest reverts back to steady state in period $t=4$. Observe that the evolution of a variable in a given contingency, prior to the shock reverting to steady state, depends on expectation about the evolution of variables in all future contingencies. The purple lines represent impulse response functions (IRF). Those are weighted averages of the evolution of each variable and correspond to the expectation agents hold about the economy in the initial period after the shock has been realised.

\subsection{Implementing the Optimal Commitment in Eggertsson and Woodford (2003) via a Price Level Target and a Nominal GDP Target}

In Figure 2 we compare the optimal commitment to the standard Taylor rule (TTR) using the numerical values assumed in EW2003. As emphasised in that paper, the Taylor rule, or equivalently a strict inflation target, results in a large output drop (about 15 percent) and drop in inflation (about 10 percent) at the ELB. The OCP - via the central bank committing to keeping the nominal interest rate low for a substantial period of time - eliminates most of the drop in output. EW2003 also shows that a policy rule that fully implements this equilibrium can be described as follows: at the ELB the central bank commits to not

\footnotetext{
${ }^{21}$ See Eggertsson and Woodford (2003) for more details on the derivation. We use the EW2003 parametrisation: $\theta=7.87, \sigma=0.5$, $\kappa=0.02, \beta=0.99, \lambda=\frac{\kappa}{\theta}, \mu=0.9, r_{L}^{n}=-0.005, r_{H}^{n}=\beta^{-1}-1$.
} 

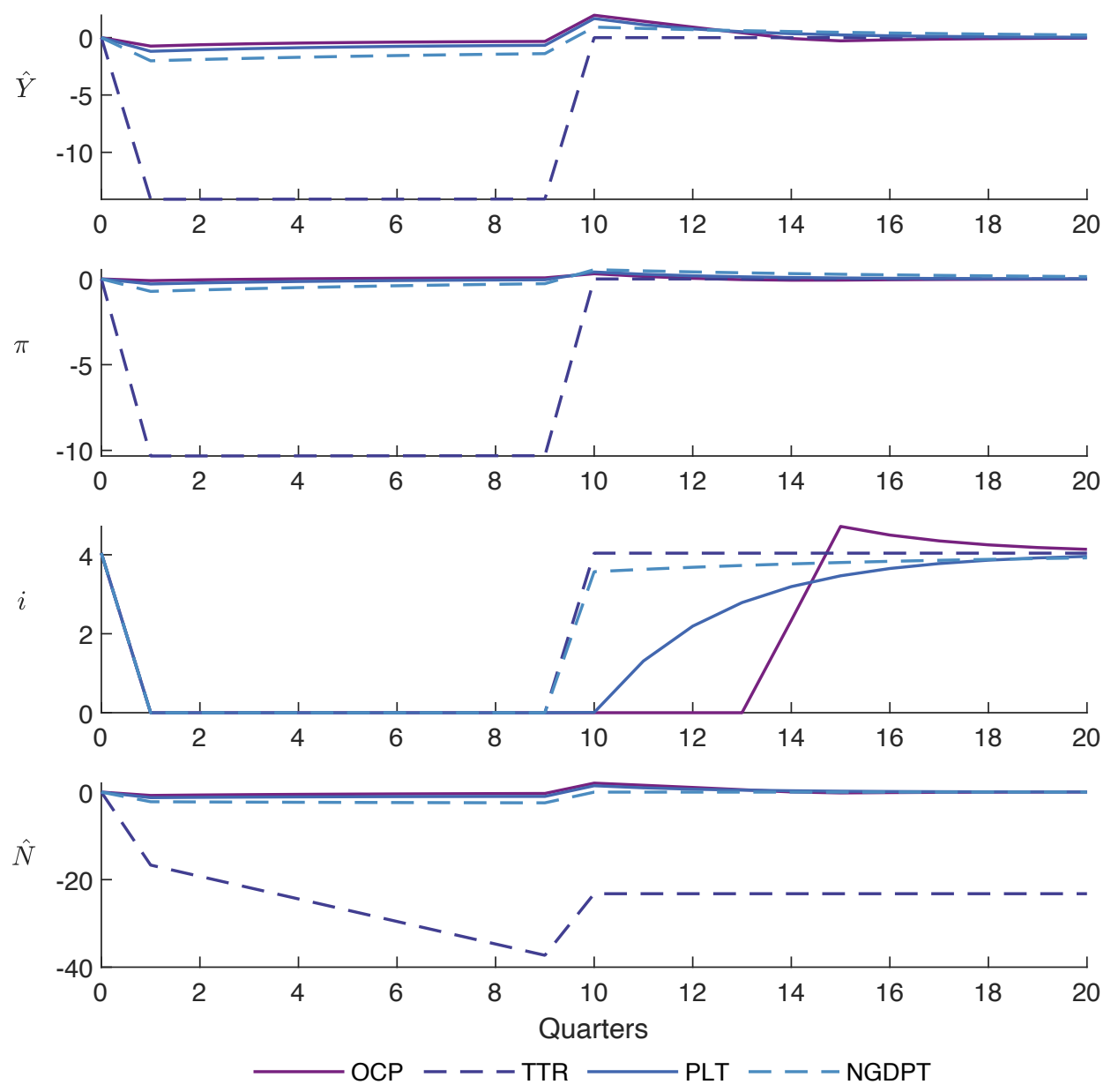

Figure 2: Selected rules and optimal commitment (OCP) under Eggertsson and Woodford (2003) calibration. Lines represent contingency 10 for output $(\hat{Y})$, inflation $(\pi)$, the nominal interest rate $(i)$, and nominal GDP $(\hat{N})$. The vertical axes report deviations from steady state, in percentage points (annualised figures). The vertical axis for the nominal interest rate reports annualised percentage points. 
increasing the interest rates unless and index $\tilde{P}_{t}$ reaches a certain threshold $\hat{P}_{t}^{*}$, i.e. $\tilde{P}_{t}=\hat{P}_{t}^{*}$ where $\tilde{P}_{t}$ is and index built as a weighted average of (detrended) output $\left(\hat{Y}_{t}\right)$, and the (detrended) price index $\left(\hat{P}_{t}\right)$ :

$$
\tilde{P}_{t} \equiv \hat{P}_{t}+\frac{\kappa}{\lambda} \hat{Y}_{t}
$$

The key to this commitment is how the threshold $\hat{P}_{t}^{*}$ is formulated. EW2003 shows that the optimal monetary policy commitment is replicated when $\hat{P}_{t}^{*}$ is computed according to the following formula:

$$
\hat{P}_{t+1}^{*}=\hat{P}_{t}^{*}+\beta^{-1}(1+\kappa \sigma) \Delta_{t}-\beta^{-1} \Delta_{t-1}
$$

where $\Delta_{t}$ is a variable that measures how much the monetary authority misses its target in period $t$ due to the ELB:

$$
\Delta_{t} \equiv \hat{P}_{t}^{*}-\tilde{P}_{t}
$$

EW2003 recognises that this rule might be difficult to communicate in practice. Hence, the authors suggest a simplified variation of the optimal rule:

$$
\hat{P}_{t}+\frac{\kappa}{\lambda} \hat{Y}_{t}=\hat{P}^{*} \quad \forall t
$$

Now the gap-adjusted Price Level Target (PLT) is fixed at all times. Figure 2 shows that this simplified policy rule does a relatively good job in replicating OCP. The reason is that the fall in the price level through the duration of the shock induces the central bank to promise a policy easing once the disturbance has subsided. Thus, the interest rate remains at its lower bound even once the shock has reverted, and inflation and output gap could be set at their steady state values. This is the key feature of the optimal policy commitment. As stressed by Woodford (2012), targeting nominal GDP instead of the price level has the same essential features. This kind of policy has been suggested by a number of authors such as Hatzius and Stehn (2011) and Sumner (2012). A Nominal GDP Target (NGDPT) can be written as:

$$
\hat{P}_{t}+\hat{Y}_{t}=\hat{Y}^{*}
$$

which would be equivalent to the simplified price level target in EW2003 for special values of $\lambda$. Figure 2 shows that this policy does a relatively good job in replicating the optimal commitment in the EW2003 numerical example. Again, the key to this result is that the fall in the price level implies a substantial monetary easing even once the shock has reverted back to steady state, as mandated by the optimal policy commitment.

\subsection{The Great Recession and the Robustness of Nominal GDP and a Price Level Target}

The key take-away from the last section was that the simple Price Level Target suggested in EW2003 and the Nominal GDP Target replicated the optimal commitment policy relatively well in the EW2003 numerical example. As we discussed, this is explained by the fact that the fall in the price level generates a commitment to lower future nominal interest rates once the shock has reverted to steady state, while a standard Taylor rule would imply an immediate normalisation.

A key feature of the EW2003 calibration, however, is that if one assumes standard policy rules, such as the Taylor rule, there is a substantial fall in the price level of about 10 percent per year, as shown in Figure 
2. Meanwhile, in the U.S. Great Recession, the fall in the price level was much smaller by most accounts. Inflation, as measured by Personal Consumption Expenditure for example, averaged at about 1.5 percent from 2008 to 2015, when the Federal Reserve started raising rates, which is only -0.5 percent below its 2 percent inflation target. This is in sharp contrast to the 10 percent drop in inflation predicted by the EW2003 parametrisation.

We now analyse the performance of the PLT and NGDPT rules once we calibrate the model to match a smaller drop in inflation. For this experiment, we interpret ${ }^{22}$ inflation as the deviation of inflation from target, as in Benigno, Eggertsson and Romei (2020). ${ }^{23}$

To parameterise the model, we calibrate $\kappa$ and $\sigma$ as in EW2003. Moreover, we assume the presence of a cost push shock $u_{t}$ that is perfectly correlated with the natural rate of interest and thus follows the same two-state Markov process we have already discussed. ${ }^{24}$ We then choose both $r_{L}$ as well as $u_{L}$ in order to match a drop in inflation of -0.5 percent and output of -7.5 percent, thus taking on different values relative to EW2003. ${ }^{25} \mathrm{~A}$ key assumption is that we suppose that policy was conducted according to the Taylor rule in this period. This calibration strategy results in $r_{L}=-0.013875$ and $u_{L}=0.00136375$.

The idea behind the calibration is that the shock that gave rise to the Great Recession - for example a debt-deleveraging shock or a similar displacement originating in the financial sector - simultaneously leads to a cost push and a drop in the natural rate of interest. While we model this in a reduced form, it is also the explanation given for the lack of deflation during the Great Recession in Eggertsson and Krugman (2012), who derive a fully specified microfoundation. ${ }^{26}$ Our approach is also consistent with the estimated DSGE model in Christiano, Eichenbaum and Trabandt (2015).

As an alternative to choosing a cost push shock to match the limited drop in inflation, we experiment with different values of $\kappa$, the slope of the New Keynesian Phillips curve (13), that generate the small drop in inflation observed in the data. We show in Section 4.9 that our conclusions are robust to this alternative strategy.

We also change the EW2003 calibration in another important respect. The objective of the central bank in EW2003 is:

$$
\mathbb{E}_{0} \sum_{t=0}^{\infty} \beta^{t}\left[\hat{\pi}_{t}^{2}+\lambda \hat{Y}_{t}^{2}\right]
$$

A well-known feature of the standard NK model is that it places virtually no weight on output in the welfare objective of the government. In the EW2003 calibration, while the weight on the squared deviation of inflation from target is one, the weight on output is only $\lambda=\kappa / \theta=0.0025$. Here instead we assume equal weights on annual inflation and on output, so that $\lambda=1 / 16$.

The reason for making this alternative assumption is two-fold: first, the Federal Reserve typically interprets itself as adhering to a dual mandate, with inflation only being one component and some measure of economic activity the other. These two objectives are typically put on equal footing. Thus, one could argue that an equal weight better captures the behaviour of the Fed in practice. Second, recent

\footnotetext{
${ }^{22}$ To stay consistent with the previous Section, we stick to the Eggertsson and Woodford (2003) calibration of $\beta=0.99$ and $\bar{\pi}=0$, which implies a steady state real and nominal rate of $4 \%$. Numerical results are almost unchanged if we set $\beta=0.995$ and $\bar{\pi}=2 \%$, implying a real rate of $2 \%$ and a nominal rate of $4 \%$.

${ }^{23}$ See Benigno, Eggertsson and Romei (2020) for the microfoundations of price setting for this interpretation.

${ }^{24}$ Equation (13) becomes $\hat{\pi}_{t}=\beta \mathbf{E}_{t} \hat{\pi}_{t+1}+\kappa \hat{Y}_{t}+u_{t}$.

${ }^{25}$ The rationale for these values is discussed in Eggertsson and Egiev (2020).

${ }^{26}$ In that paper, a cost push is traced back to the effect of the debt-deleveraging shock on the labour supply of borrowers and savers.
} 
research suggests that once one incorporates realistic idiosyncratic shocks in firms' pricing decisions, then the weight on output relative to inflation increases substantially. Eggertsson and Inui (2020) show how to microfound a loss function that puts equal weight on inflation and output (other examples in this literature are Burstein and Hellwig 2008 and Nakamura et al. 2018).
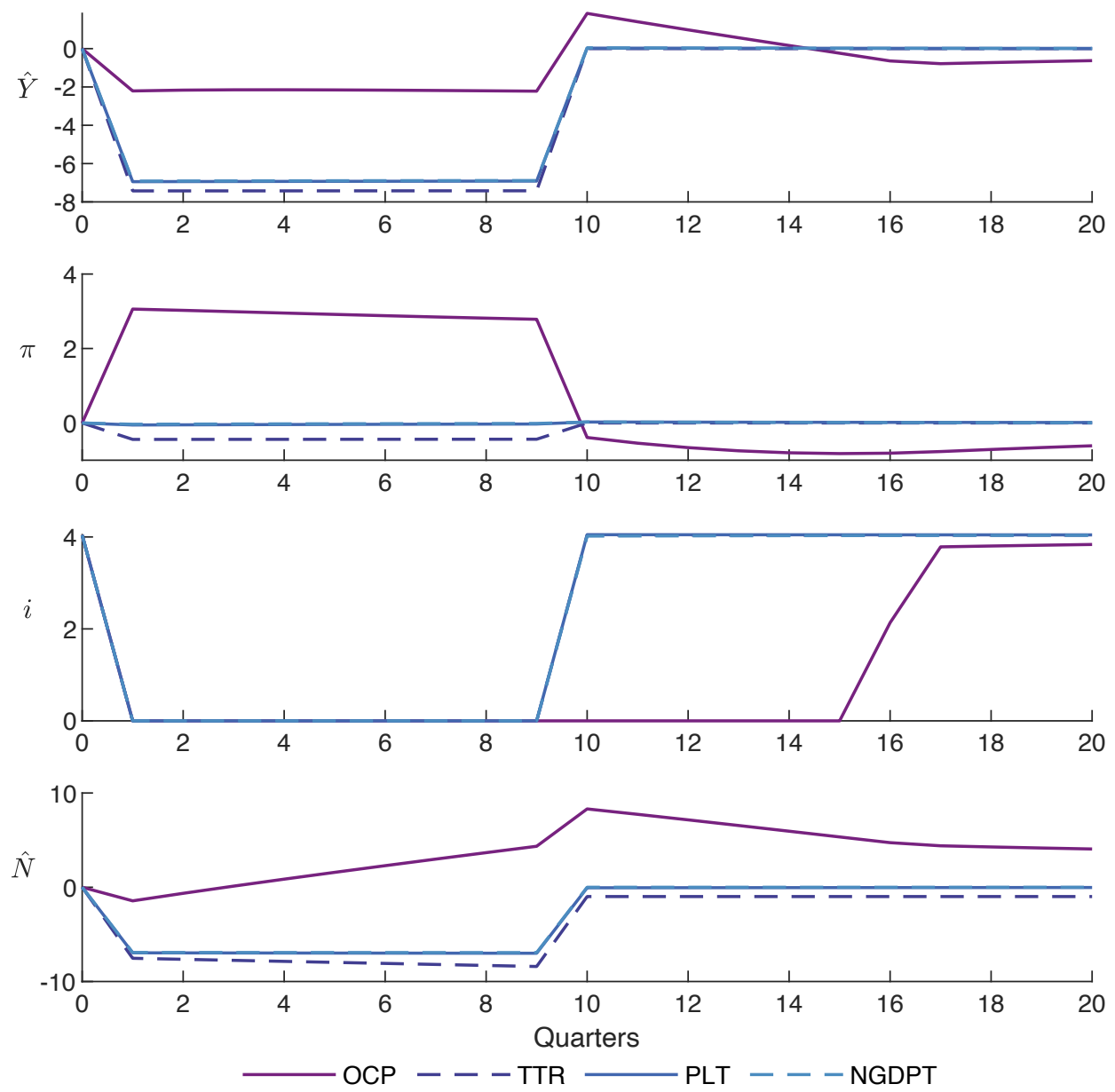

Figure 3: Selected rules and optimal commitment (OCP) under the baseline calibration with cost push shock. Coloured lines are contingency 10 for output $\left(\hat{Y}_{t}\right)$, inflation $(\pi)$, the nominal interest rate $(i)$, and nominal GDP $(\hat{N})$. The vertical axes report deviations from steady state, in percentage points (annualised figures). The vertical axis for the nominal interest rate reports annualised percentage points. The list of acronyms is detailed in Table 1.

Figure 3 contrasts the optimal policy commitment (OCP) to the Taylor rule (TTR) under our main calibration strategy, showing the contingency when the natural rate of interest reverts back to steady state ten quarters after the shock hits (other contingencies look qualitatively similar). Assuming the Federal Reserve follows a Taylor rule implies, by construction, a fall in inflation of 0.5 percent and a drop in output of 7.5 percent. The optimal commitment, in contrast, results in only a 2 percent drop in output and, instead of falling, inflation overshoots its target substantially throughout the duration of the shock. The way the central bank accomplishes this is by committing to keeping the nominal interest rate at the ELB by about six additional quarters after the natural rate normalises, a similar commitment as in the original EW2003 example. Interestingly, this commitment now implies that during the period of the shock inflation overshoots its target by about 3 percentage points and then mildly undershoots it once the disturbance subsides. This is in sharp contrast to the EW2003 calibration, where there is no such overshooting of the inflation target when the shock hits. The reason for the different result is that the 
central bank is now putting output deviation and inflation on equal footing in its objective. Accordingly, it is more willing to tolerate higher inflation in order to achieve better output stabilisation.

Figure 3 also shows the outcome if the central bank follows a Price Level Target (PLT) of the form suggested by EW2003 and a Nominal GDP Target (NGDPT). As the Figure suggests, this commitment does not substantially improve the outcome relative to the Taylor rule. The reason is that the small decrease in the price level in this numerical experiment leads to a trivial additional commitment to low future rates once the shock has subsided. The key mechanism for why PLT succeeds in replicating the optimal commitment in the EW2003 calibration lies in the shock generating enough deflation. This means that once the disturbance is over the central bank does not raise the interest rate for a considerable period of time, or until the price level recovers to the target. If there is very little fall in the price level, this commitment loses most of its power. As it can be seen in the third panel, the nominal interest rate is almost the same for the Taylor rule relative to the PLT or the NGDPT. Note that this problem is attenuated by the fact that once a central bank commits to either of these two policies, the equilibrium drop in the price level is even smaller than under the Taylor rule, thus implying an even smaller commitment to future expansion once the shock reverts to steady state.

A stark assumption in the calibration of the Markov process is that the Federal Reserve followed a Taylor rule during the crisis. This interpretation implies that the forward guidance done by the central bank during the crisis did not substantially commit to keeping future rates lower as inflation started to recover. By contrast, if we calibrate the model taking the other extreme - that policy was conducted under optimal commitment - then the implied fall in the price level would have been larger under alternative policy regimes, such as the Taylor rule, and thus price and nominal GDP targeting would have worked better. We prefer our specification, however, as it more clearly highlights possible pitfalls of these targeting strategies. They critically rely upon a sizeable fall in inflation in order to generate any meaningful commitment to low future rates. In the presence of cost push shocks, or very low values for $\kappa$, there is no reason to expect such a fall in the price level from the perspective of the model.

\subsection{Cumulative Nominal GDP Targeting and Symmetric Dual-Objective Targeting}

We now consider simple alternatives to the price level and nominal GDP targeting rules that better replicate the optimal commitment policy.

The key problem with both rules was that if there is little decrease in the price level, neither rule implies much accommodation once the shock giving rise to the ELB normalises. The optimal commitment, instead, mandates that if there is a decrease in either output or the price level for the duration of the ELB, then there should be accommodation (or make-up accommodation) once the crisis period is over, as seen in the analytic derivation of the fully optimal targeting rule. In that derivation, the time varying target is defined in terms of the weighted average of the price level and output. Moreover, if the target is missed, the fully optimal rule suggests that the future target should be increased, thus generating expectations of future accommodation.

Motivated by this observation, let us first consider the following simple targeting rule. ${ }^{27}$ Define the cumulative deviations of nominal GDP from its trend as $\hat{\Gamma}_{t}$ :

$$
\hat{\Gamma}_{t}=\hat{P}_{t}+\hat{Y}_{t}+\hat{\Gamma}_{t-1}
$$

\footnotetext{
${ }^{27}$ This rule is closely related to Reifschneider and Williams (2000), see Section 4.5.
} 

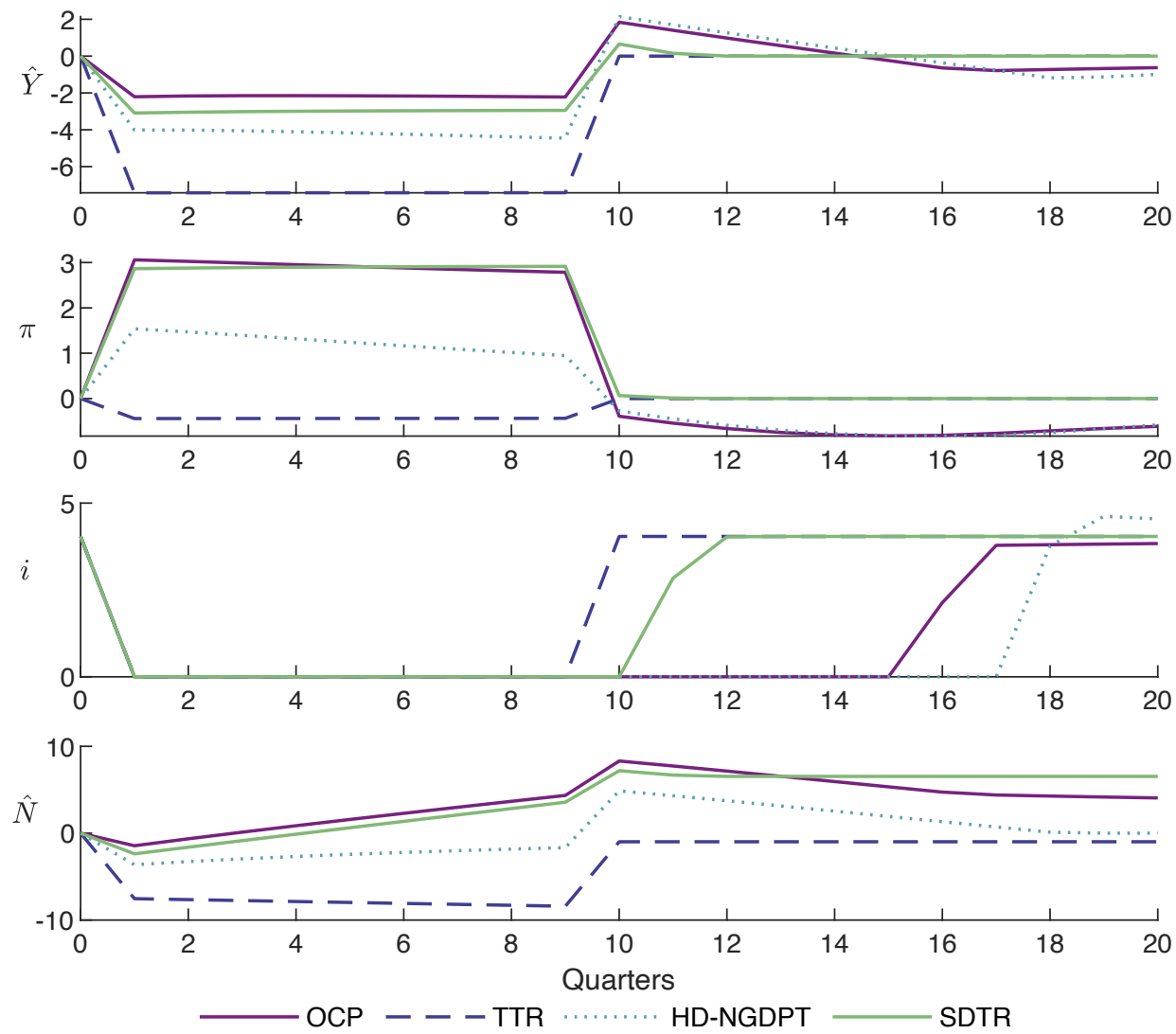

Figure 4: Selected rules and optimal commitment (OCP) under baseline calibration with cost push shock. Coloured lines are contingency 10 for output $(\hat{Y})$, inflation $(\pi)$, the nominal interest rate $(i)$, and nominal GDP $(\hat{N})$. The vertical axes report deviations from steady state, in percentage points (annualised figures). The vertical axis for the nominal interest rate reports annualised percentage points. The list of acronyms is detailed in Table 1. 
This variable measures how much nominal GDP deviates from its target. Relative to previous nominal GDP targeting proposals, such as those cited above, this variable keeps track not only of the size of deviations of current nominal GDP from its trend, but it also accounts for past misses. The proposed targeting rule is then to set the nominal interest rate so that the cumulative nominal GDP is on trend, i.e. $\hat{\Gamma}_{t}=0$, whenever possible. Otherwise, the central bank should set the nominal rate at its effective lower bound, with the threshold for lift-off being that the cumulative nominal GDP target is reached again. Critically, if this rule is credible, the public understands that if the Federal Reserve misses its nominal GDP target, it is then committed to keeping the interest rate at zero until it has compensated for having missed its target. Thus, if it were to miss on trend nominal GDP by 5 percent, it is committed to overshoot trend nominal GDP by 5 percent going forward.

Figure 4 shows how this History-Dependent Nominal GDP Target (HD-NGDPT) does in the numerical experiment. It does substantially better than PLT or NGDPT reported in Figure 3 (we provide a more detailed assessment of this comparison in Table 2). The key to the success of this rule is that it prescribes a substantial easing once the ELB is no longer binding on account of the exogenous shock, much as prescribed by the optimal commitment.

As an alternative to keeping track of how nominal GDP misses its trend, we also consider the following: ${ }^{28}$ let us define an index $\left(\hat{D}_{t}\right)$ that measures how inflation and real output deviates from trend:

$$
\hat{D}_{t}=4 \hat{\pi}_{t}+\hat{Y}_{t}+\hat{D}_{t-1}
$$

A targeting rule we coin Symmetric Dual-Objective Targeting Rule (SDTR) sets interest rates so that the Dual Mandate Index $\hat{D}_{t}$ is set to zero if possible but keeps the nominal interest rate at the ELB otherwise. ${ }^{29}$ Critically then, if a central bank following this reaction function misses its target, it will automatically commit to a future accommodation.

Figure 4 shows the performance of this rule and illustrates that it does even better than the cumulative nominal GDP target. Again, the key behind this success is that it implies a considerable easing once the ELB is no longer binding, much beyond price or nominal GDP targets. PLT and NGDPT imply make-up behaviour for past misses of the inflation target only. The two new rules show this feature as well, but in addition they do the same for output: if there is a recession today, the central bank then commits to a boom in the future. This type of commitment is particularly important when the price level moves by small amounts.

Overall, the fact that SDTR does better than HD-NGDPT is not robust once we consider richer model such as the FRBNY DSGE. Before getting there, however, we compare these rule to other well-known policy rules and offer a more detailed assessment of their performance.

\subsection{Comparison to Other Policy Rules}

In this Section we compare the two policy rules we have suggested to several reaction functions that have been proposed in the literature (Table 1). We summarise their performance in Table 2, using the welfare criterion specified in Equation (25), as well as other measures. The first column shows the welfare loss implied by these different rules, with the optimal monetary policy commitment normalised to one.

\footnotetext{
${ }^{28}$ The rule is closely related to Reifschneider and Williams (2000), see Section 4.5, and rules that feature a lagged interest rate, as in Taylor and Williams (2010) or recently discussed in Kiley and Roberts (2017).

${ }^{29}$ The inflation gap is multiplied by 4 to make sure that there is equal weight on annualised inflation and output.
} 


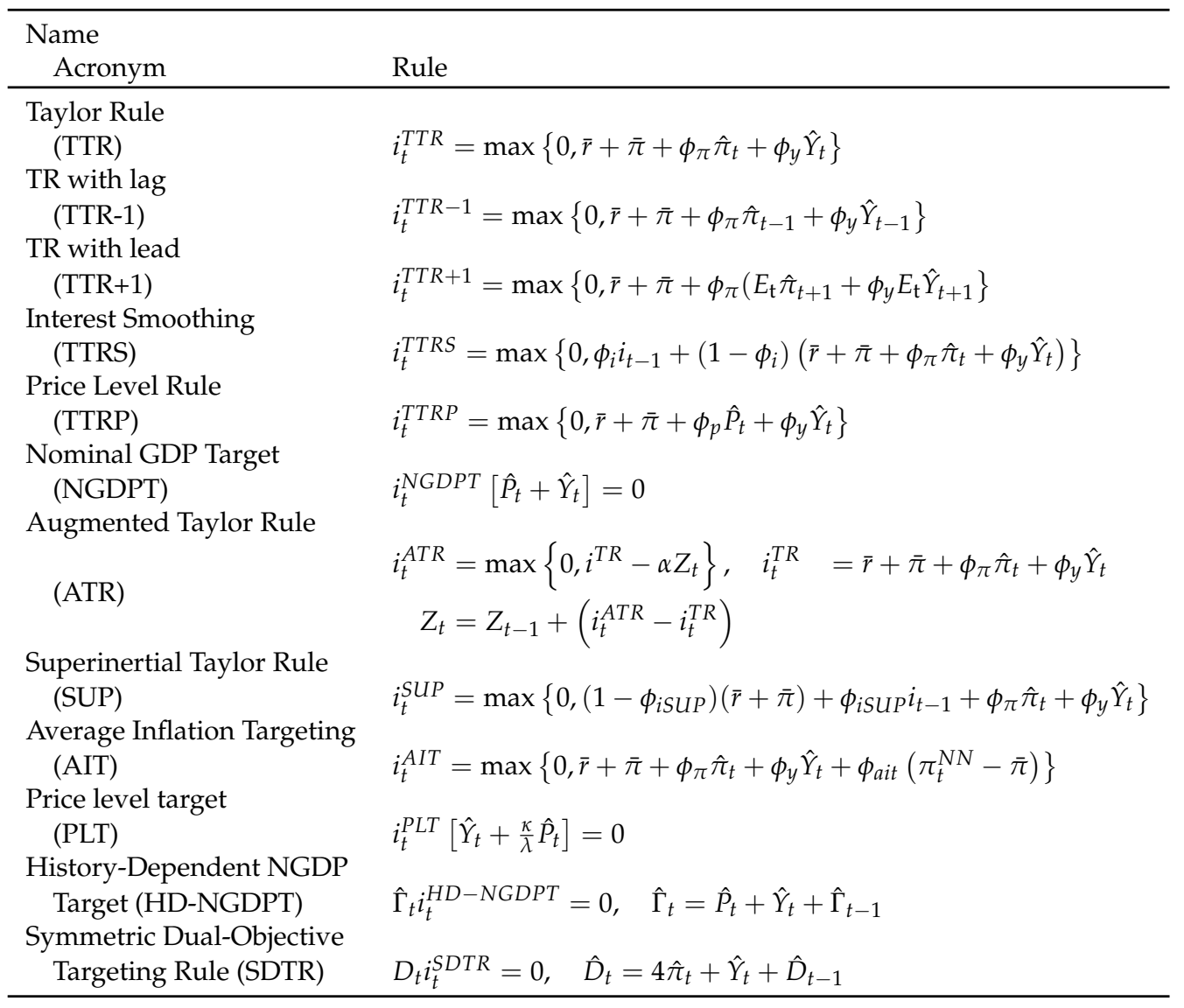

Table 1: Policy rules, names, and acronyms. $\pi_{t}^{N N}$ is average inflation over last $N N$ quarters. $\hat{P}_{t}$ is deviation of price level from its (detrended) steady state value. $\hat{\Gamma}_{t}$ and $\hat{D}_{t}$ are defined in Equation (26) and (27). 
Of the rules considered, the two we have introduced in Section 4.4 are among the best performing ones, together with the Augmented Taylor Rule (ATR) proposed by Reifschneider and Williams (2000) and the Superinertial Taylor Rule (SUP) described in Rotemberg and Woodford (1999). Figure 5 depicts the dynamic response of the simple two-equation model under these different reaction functions, alongside two benchmarks: the Optimal Commitment Policy (OCP) and a Truncated Taylor Rule (TTR). We discuss each one in turn.

The Augmented Taylor Rule is closely related to our two proposals. According to this rule, a cumulative index $\left(Z_{t}\right)$ keeps track of how much the actual interest rate misses the interest rate suggested by the standard Taylor rule due to the ELB. This reaction function then prescribes the interest rate to respond to these cumulative misses at a rate $\alpha$. In turn, this implies that if the ELB is binding, future rates will be lower than predicted by a standard Taylor rule to make up for previous deviations from target. This is a similar make-up feature to the one characterising the fully optimal commitment rule in EW2003, as well as our proposed rules HD-NGDPT and SDTR.

The Superinertial rule of Rotemberg and Woodford (1999) generates a similar commitment to low rates for a prolonged period of time, but for different reasons. As shown in Table 1, it has a lagged interest-rate term appearing in an otherwise standard Taylor rule. The coefficient on this lagged interest rate, however, is greater than one - hence the name super-inertial. This implies not only that interest rates drop very slowly in reaction to the shock, as shown in Figure 5, but also that they increase equally sluggishly once the disturbance reverts. This generates exactly the type of commitment needed. Interestingly, even though this rule does not prescribe an immediate drop in the nominal interest rate in reaction to the shock - as the optimal commitment would mandate - it still outperforms most of the other policy functions under consideration.

In line with the finding of Reifschneider and Wilcox (2019), we can also document how a Taylor-type rule reacting to Average Inflation (AIT) is sub-optimal at best, with a welfare loss comparable to a price level or nominal GDP target. Again, this is mostly due to the limited drop in inflation that prevails in this parametrisation of the model. This policy rule is arguably similar to the policy regime adopted by the Federal Reserve in 2020.

Appendix A.6.1 shows the results if we do not impose the ELB and the nominal interest rate is allowed to go negative. Our two proposed rules are still among the best performing ones. There are two notable observations: first, NGDPT and HD-NGDPT overlap in this case. The central bank can fully stabilise nominal GDP, and thus there will never be a cumulative deviation to be made up for; second, the price level targeting rule PLT performs very well. This should not come as a surprise, as Eggertsson and Woodford (2003) show that optimal commitment is identical to PLT if the effective lower bound is never reached.

In the next sections we assess the robustness of these conclusions to different assumptions in terms of size of the inflation response, its source, choice of policy parameters, as well as how our results transpose to a more sophisticated macroeconomic model.

\subsection{Forward Guidance, the Role of Uncertainty and Time Dependent Policy Com- mitments}

The toolkit allows us to evaluate the robustness of different policy strategies in the presence of uncertainty. This is particularly helpful to clarify the difference between Time-Dependent Forward Guidance, under 

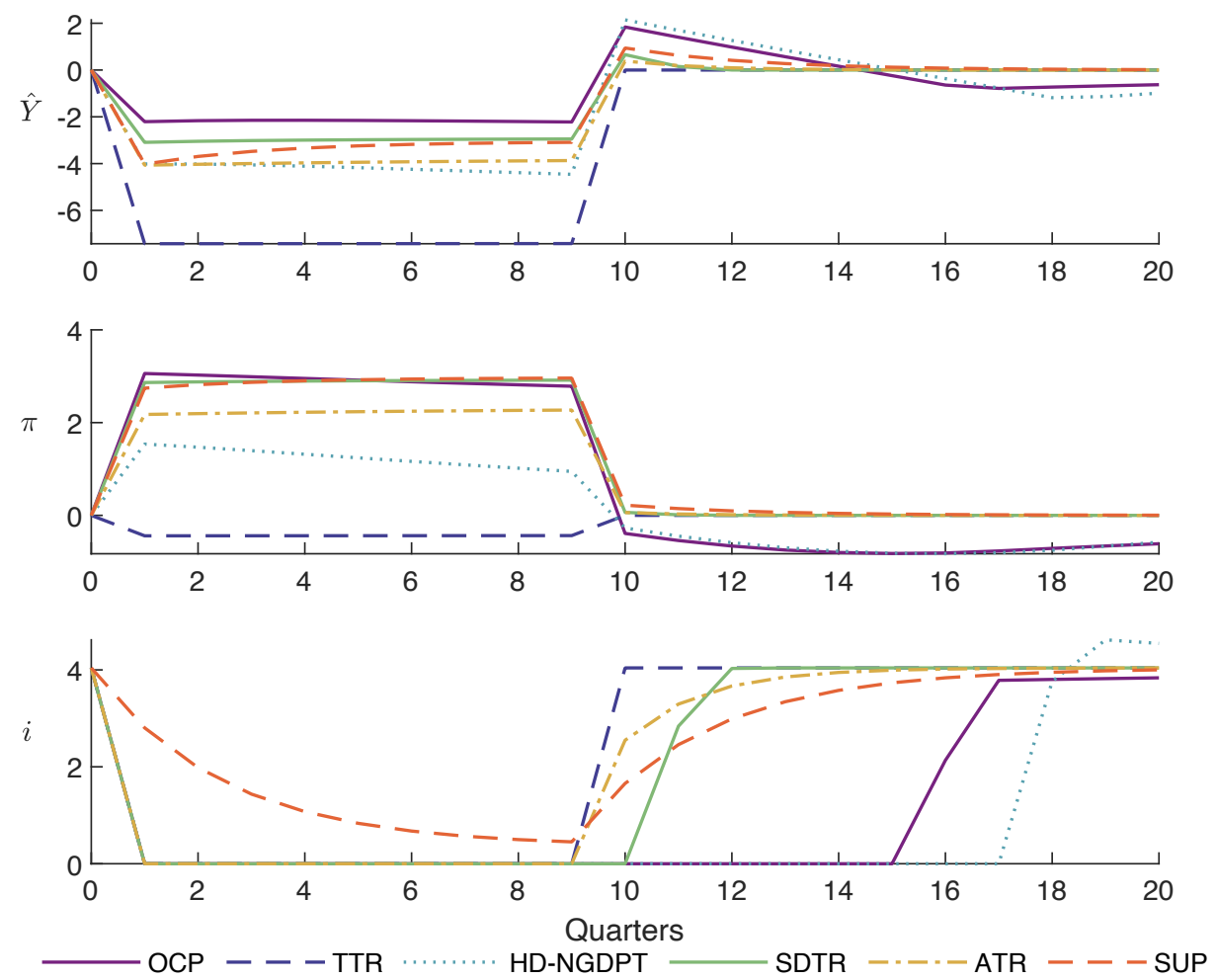

(a) Paths for output $(\hat{Y})$, inflation $(\pi)$ and nominal interest rate $(i)$
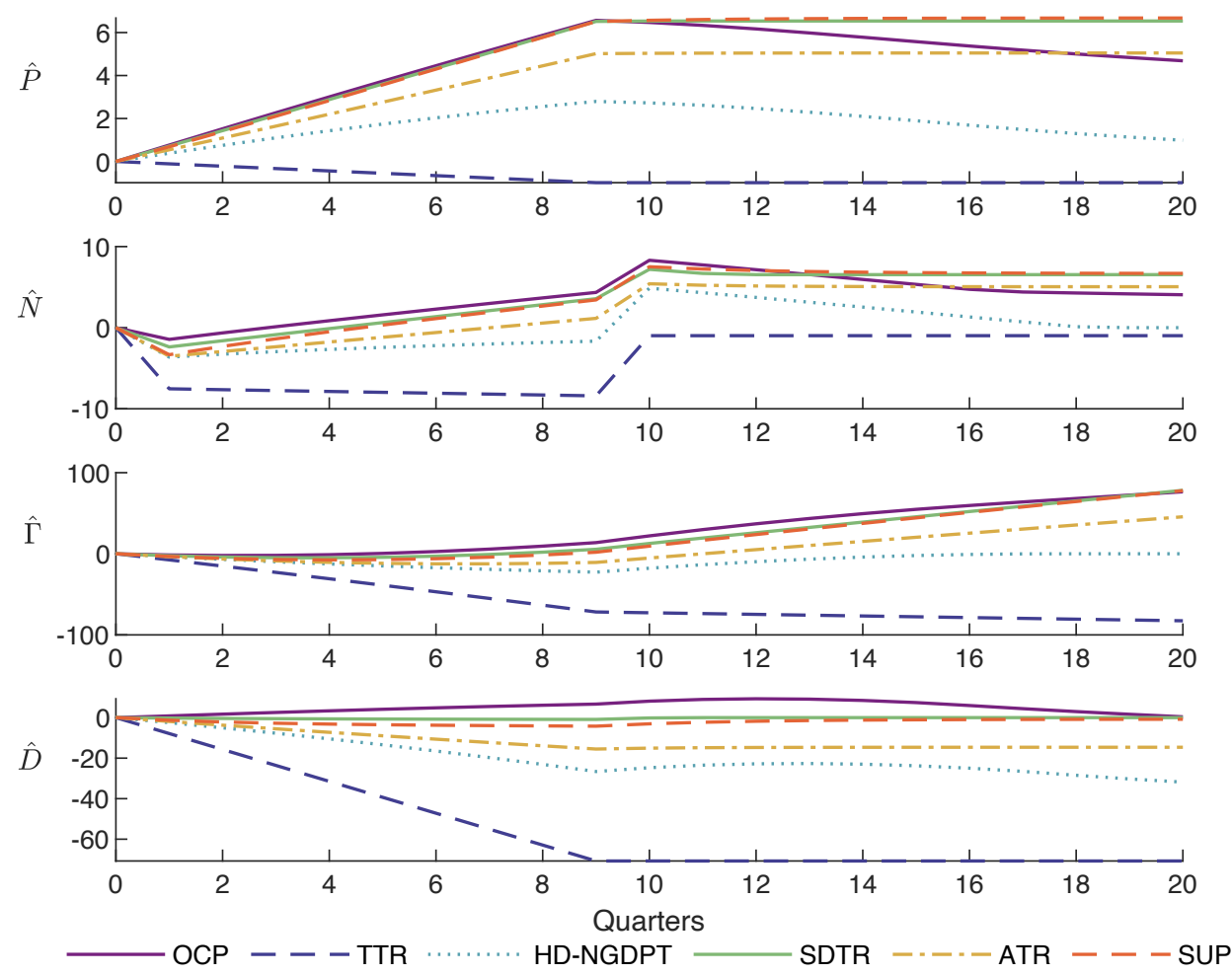

(b) Paths for price level $(\hat{P})$, nominal output $(\hat{N})$, cumulated nominal output $(\hat{\Gamma})$ and the symmetric mandate index $(\hat{D})$

Figure 5: Dynamic response to a natural interest rate shock and a correlated cost push shock in a simple two-equation NK model, under different policy rules. Shocks are calibrated such that output falls by $7.5 \%$ and inflation by $0.5 \%$ constant under a Truncated Taylor Rule (TTR). The natural interest rate reverts to the absorbing state after 10 quarters (10th contingency). The vertical axes report percentage deviations from steady state (annualised figures). The vertical axis for $i$ reports annualised percentage points. The list of acronyms is detailed in Table 1 . The parametrisation is reported in Table A.2. Paths for additional rules reported in Table 1 are shown in Section A.7.1 in the Appendix. 


\begin{tabular}{|c|c|c|c|c|c|c|c|}
\hline & $\begin{array}{c}\text { Welfare Loss } \\
\text { (1) }\end{array}$ & $\begin{array}{c}\mathbb{E}_{0}\left[\tau+k_{\tau}-\tilde{T}\right] \\
(2)\end{array}$ & $\begin{array}{c}\text { Volatility } \hat{Y} \\
\text { (3) }\end{array}$ & $\begin{array}{l}\text { Volatility } \pi \\
\text { (4) }\end{array}$ & $\begin{array}{c}\text { Volatility } i \\
\text { (5) }\end{array}$ & $\begin{array}{l}\text { Impact } \hat{Y} \\
\text { (6) }\end{array}$ & $\begin{array}{l}\operatorname{Impact} \pi \\
\text { (7) }\end{array}$ \\
\hline OCP & $8.25210^{-4}$ & 15.257 & $5.35610^{-3}$ & $4.90410^{-4}$ & $1.41110^{-3}$ & -2.208 & 3.059 \\
\hline \multicolumn{8}{|c|}{ PANEL A: baseline rules } \\
\hline OCP & 1.000 & 1.000 & 1.000 & 1.000 & 1.000 & 1.000 & 1.000 \\
\hline TTR & 3.800 & 0.655 & 9.335 & 0.022 & 0.657 & 3.364 & -0.144 \\
\hline HD-NGDPT & 1.568 & 1.099 & 3.563 & 0.207 & 1.094 & 1.818 & 0.502 \\
\hline SDTR & 1.194 & 0.703 & 1.514 & 0.975 & 0.716 & 1.400 & 0.936 \\
\hline ATR & 1.404 & 0.655 & 2.603 & 0.586 & 0.666 & 1.842 & 0.711 \\
\hline SUP & 1.352 & 0.000 & 1.896 & 0.980 & 0.426 & 1.820 & 0.897 \\
\hline \multicolumn{8}{|c|}{ PANEL B: additional rules } \\
\hline PLT & 3.294 & 0.655 & 8.118 & 0.000 & 0.657 & 3.145 & -0.018 \\
\hline NGDPT & 3.267 & 0.655 & 8.054 & 0.000 & 0.657 & 3.132 & -0.011 \\
\hline TTRP & 4.183 & 0.000 & 10.301 & 0.007 & 0.199 & 3.894 & -0.136 \\
\hline TTRS-1 & 1.520 & 0.000 & 2.671 & 0.734 & 0.363 & 2.189 & 0.759 \\
\hline TTR-1 & 1.835 & 0.649 & 4.177 & 0.236 & 0.653 & 2.451 & 0.454 \\
\hline AIT & 3.306 & 0.655 & 8.149 & 0.000 & 0.657 & 3.150 & -0.021 \\
\hline FLFG & 3.499 & 0.807 & 8.596 & 0.020 & 0.814 & 2.752 & 0.042 \\
\hline
\end{tabular}

Table 2: Some metrics for selected interest rate rules in the simple two-equation NK model in the presence of a natural rate shock and a correlated cost push shock. All rows except the first show values normalised with respect to the optimal commitment policy (OCP, first row). Column (1) reports the welfare loss computed from a quadratic loss function (Equation 25) for the central bank with equal weights; Column (2) displays the unconditional expected duration of the Effective Lower Bound (regimes 1 and 2); Columns (3)-(5) report a summary measure of deviations of the endogenous variables from target, computed according to Equation (A.6); finally, Columns (6) and (7) show the response on impact, in annual percentage points, of the output and inflation to a natural interest rate shock and a correlated cost push shock such that output falls by 7.5 percent and inflation by 0.5 percent under a Truncated Taylor Rule (TTR). Rule calibration reported in Table (A.2). The model is calibrated with the standard EW2003 parameter values reported in footnote 21 . The list of acronyms is detailed in Table 1.

which the central bank communicates a time period when it expects the ELB to be binding, and StateContingent Forward Guidance, where the monetary authority stipulates economic conditions - or thresholds - which once satisfied allow the interest rate to be lifted from the ELB.

A popular policy strategy followed by policy-makers shortly after the Financial Crisis of 2007-08 - aimed at providing additional monetary stimulus - was to stipulate that the policy rate would remain at zero until a predetermined calendar time. The Bank of Canada, for example, announced on 21 April 2009 that its policy rate would remain at zero until the end of the second quarter of 2010. The Federal Reserve initially pursued a similar time-dependent strategy by stating that rates would stay low for "some time" (December 2008), for an "extended period" (March 2009) and finally "at least to mid-2013" (August 2011).

While the Bank of Canada and the Federal Reserve did their best to communicate that these time commitments were conditional on incoming data, a common criticism was that the markets interpreted this as a binding commitment, regardless of actual trajectory of the economy. This is a point raised by Woodford (2012).

One interpretation of time-dependent forward guidance is that it corresponds to the optimal fixed duration of the zero interest rates determined at time $t=0$, what we call the optimal Fixed-Length Forward Guidance (FLFG). Under FLFG, the monetary authority announces that, in response to a negative natural rate shock, it holds the nominal rates at zero until a fixed calendar date $v$, after which the policy will 
return to a standard Taylor rule. This corresponds to the following policy rule for nominal rates

$$
i_{t}= \begin{cases}0 & \text { for } t \leq v \\ \max \left(0, \bar{r}+\phi_{\pi} \pi_{t}\right) & \text { otherwise }\end{cases}
$$

Figure 6 shows the optimal time-zero FLFG assuming a deterministic process for the natural rate of interest and contrasts it to the optimal policy commitment. As the fFigure reveals, FLFG approximates OCP relatively well by approximating a delayed lift-off of the policy rate.

As stressed by Woodford (2012) however, a key problem with time-dependent forward guidance is that it does not allow the central bank to flexibly react to economic conditions, i.e. to the shocks that brings the economy to the ELB in the first place. Since the toolkit can incorporate a stochastic duration of the ELB episode, it is ideal to clarify this point.
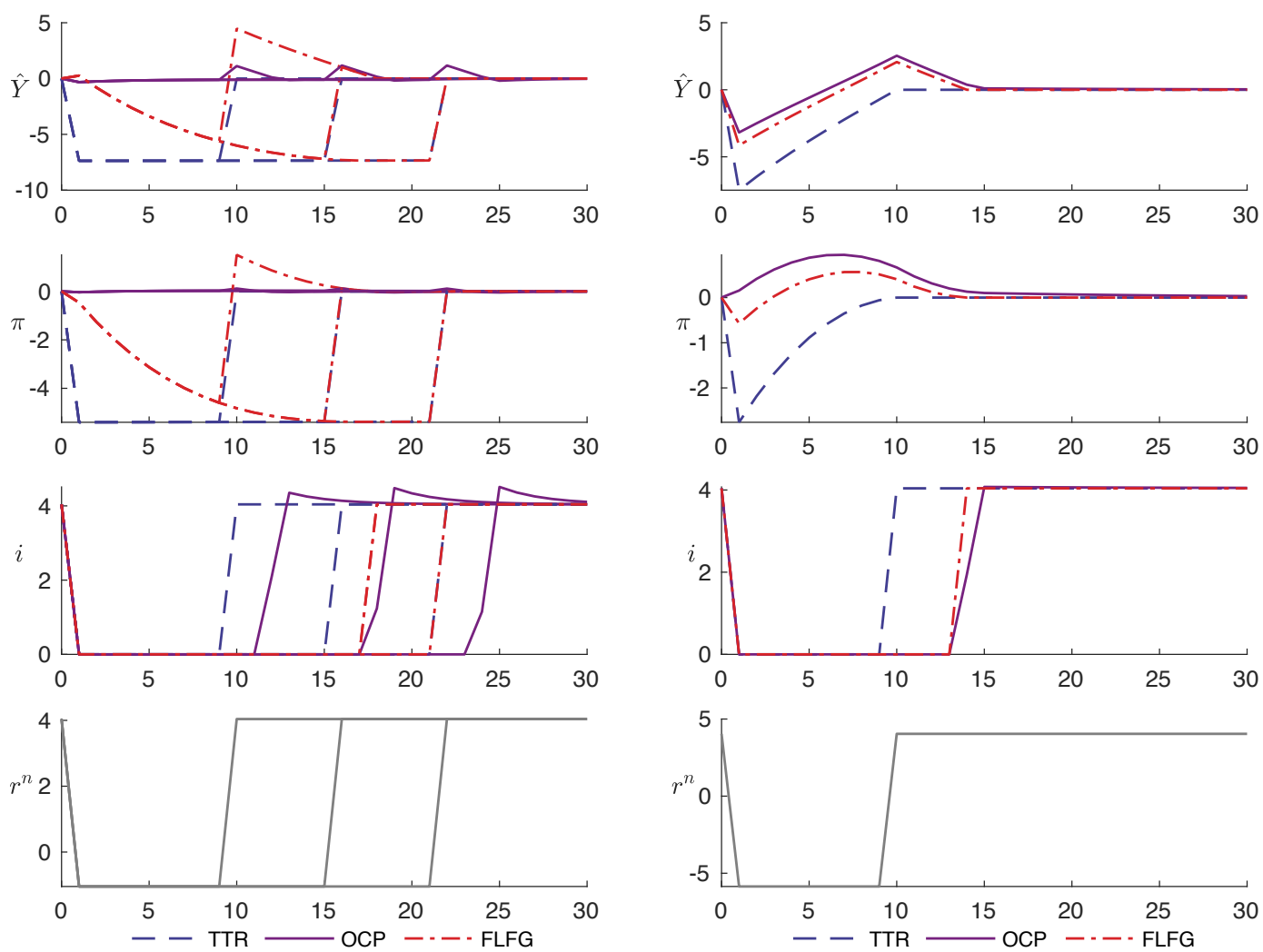

(a) Natural rate $r^{n} \sim$ stochastic two-state Markov

(b) Natural rate $r^{n} \sim$ deterministic two-state Markov

Figure 6: Optimal Fixed-Length Forward Guidance (FLFG, red dot-dash line) under alternative solutions for the two-state Markov natural interest rate disturbance: stochastic (Panel a, left) or deterministic process (Panel b, right). Lines represent impulse responses for output $(\hat{Y})$, inflation $(\pi)$, the nominal interest rate $(i)$ and the natural rate $\left(r^{n}\right)$. Panel (a) shows contingency 10, 16 and 22 for each policy rule. At contingency 16, the central bank moves away from the ELB under both optimal commitment (OCP) and fixed-length forward guidance (FLFG). The size of the Markov shock process is calibrated to achieve a drop in output in the initial period of $-7.5 \%$ under a Taylor rule (blue dashed line). The purple solid line reports the optimal policy under commitment (Ramsey plan). The vertical axes for $\hat{Y}$ and $\pi$ report deviations from steady state, in percentage points (annualised figures). The vertical axes for $i$ and $r^{n}$ report annualised percentage points.

Figure 6 compares FLFG with OCP assuming the two-state Markov process analysed in previous sections. As evident from the Figure, FLFG now does a much poorer job in replicating the OCP when the duration of the shock is uncertain. The Figure shows the realisations for output, inflation, interest rates and the natural rate of interest, assuming the shock reverts to steady state in period $t=10, t=16$ and $t=22$. It is 
only for the 16th contingency that the duration of the ELB under OCP and FLFG coincide. If the natural rate reverts earlier (e.g. in period $t=10$ ), then FLFG implies the ELB binds for longer than under OCP, while if the natural rate stays low for longer (e.g. period $t=22$ ), then FLFG does not imply sufficient monetary stimulus since the central bank will raise rates as soon as the shock subsides.

We also contrast FLFG to the policy rules in Table 2. The optimal FLFG does worse than all other reaction functions, with the exception of the Taylor rule (TTR). The reason is that this type of commitment does not adjust the duration of the policy accommodation in reaction to shocks.

\subsection{Communicating State-Contingent Policy Rules}

One major rationale for using a time-dependent policy commitment is that it is easy to explain and communicate it to the public. Communicating a state-contingent policy rule, however, need not be much more complex.

The Federal Reserve's formulation of a threshold strategy in December 2012 is an example of a statecontingent policy commitment, that replaced the Fed's time-dependent policy. Under the new formulation, the Federal Reserve announced in its FOMC statement that it would

"keep the target range [...] at 0 to $1 / 4$ percent and currently anticipates that this [...] will be appropriate at least as long as the unemployment rate remains above 6-1/2 percent, inflation between one and two years ahead is projected to be no more than half a percentage point above the Committee's 2 percent longer-run goal."

This type of commitment resembles much more closely the fully optimal state-contingent policy.

Consider the following communication strategy:

1. The central bank announces that it will keep the interest rate at zero until a particular quantitative threshold, or targeting criterion, is met for inflation and output, similar to its policy in 2012 (further specified below). This gives the market a way of forecasting the duration of the ELB, obtained by predicting the variables contained in the target criterion;

2. Once this threshold is met and the ELB is no longer binding, the interest rate is set freely to hit the pre-specified target criterion.

As shown by EW2003, optimal commitment is implemented in the two-equation model we have sketched out if the quantitative threshold is specified using as a targeting criterion the index $\tilde{P}_{t}$, which is a weighted average of the price level and output as defined in Equation (20). The threshold this index needs to reach for lift-off is denoted by $\hat{P}_{t}^{*}$, specified in Equation (21). Observe that the threshold in period $t+1$ can be computed at time $t$, thus in each period the monetary authority can state what the threshold will be for a lift-off from the ELB going forward, based upon variables observed in period $t$.

As discussed in EW2003, a major advantage of this targeting rule is that its formulation is independent from the stochastic process for the natural rate of interest and the cost push shock. What is required of the policy-maker is to know the structural parameters of the model and values for output and the price level. The policy communication of the Federal Reserve in 2012 had this exact feature.

Our proposed make-up strategies HD-NGDPT and SDTR can be communicated along the same lines. The

only difference is that the targeting criterion is now $\hat{\Gamma}_{t}=0$, where this variable is defined in Equation (26). For HD-NGDPT it is $\hat{D}_{t}=0$, where the targeting variables is defined in Equation (27). 
To be more specific, consider HD-NGDPT and let a shock hit the economy at $t=1$. In this period, even if the central bank cuts the interest rate to the ELB, it is unable to achieve its nominal GDP target, i.e. $\hat{N}_{1}=\hat{P}_{1}+\hat{Y}_{1}<0$. At time $t=1$, the policy-maker announces that the interest rate will remain at zero at least until nominal GDP reaches the threshold $\hat{N}_{2}^{*}$ given by:

$$
\hat{N}_{2}^{*} \equiv-\hat{\Gamma}_{1}=-\hat{P}_{1}-\hat{Y}_{1}>0
$$

which exactly compensates for the shortfall in the previous period. In other words, the central bank commits to make up for the drop in nominal GDP from period $t=1$ by overshooting in period $t=2$. Consider now the scenario in which the shock remains in the low state also in period $t=2$. The monetary authority then announces that the interest rate will remain at zero at least until nominal GDP reaches the threshold:

$$
\hat{N}_{3}^{*} \equiv-\hat{\Gamma}_{2}=-\hat{P}_{2}-\hat{Y}_{2}+N_{2}^{*}>0,
$$

thus compensating for its past two misses by overshooting in future periods. As in the case of the EW2003, the advantage of this type of targeting rule is that its implementation does not depend upon the stochastic nature of the underlying shock, but rather exclusively on observable variables. Moreover, the expected duration of the ELB can automatically be inferred by market participants: the policy acts as an automatic stabiliser. Thus, for example, in the case of a fresh adverse demand shock the market will infer that the threshold is further away from being satisfied. Consequently, it will adjust its expectations to reflect a longer duration at the ELB, and in turn generate an additional monetary stimulus to counteract the shocks without the need for new announcements by the monetary authority. By contrast, in case of a time-dependent commitment the central bank would need to reformulate its policy each time in response to shocks, and the size of the adjustment would depend on the stochastic properties of the underlying disturbance.

\subsection{Odyssean and Delphic forward guidance}

Another illustration of the usefulness of accounting for uncertainty is motivated by the debate about the economic effects of central bank forward guidance. Campbell et al. (2012) distinguish between Odyssian and Delphic forward guidance: the former refers to the standard theory about forward guidance, where the central bank makes announcements about future actions and it is believed to be credible. The latter refers to the idea that forward guidance statements - for a given economic fundamental and monetary policy stance - may instead change agents' beliefs about future economic fundamentals.

Allowing for Delphic forward guidance it can happen that a central bank announcement that is supposed to be expansionary - such as keeping rates lower for longer - has in fact a contractionary effect, because private-sector agents revise downwards their beliefs about economic fundamentals.

Campbell et al. (2012) can be placed in a broader literature on the effects of information in central-bank policy. Another recent paper in this literature is Nakamura and Steinsson (2018). The information effect in their model analysis captures information about the state of the economy arising in response to surprise interest rate cuts or increases by the policy-maker. The underlying mechanism is the same: policy can affect private sector beliefs about economic fundamentals.

We conduct a small experiment that illustrates how we can coherently illustrate the effect of both types of forward guidance with the help of our toolkit. In this case, the main benefit of the toolkit is that it provides a framework where one can make a meaningful distinction between expected and realised 
duration of the ELB episode. In a deterministic setup, the two concepts coincide. This is not the case in the toolkit: here we can change the expected duration at the ELB separately from the realised duration.

Consider the following deterministic process for the natural rate of interest. It turns negative in period $t=1$ and returns back to steady state in period $t=10$. Let us allow however for the possibility that while the actual evolution of the economy will always feature a reversal of the shock in period $t=10$, agents believe that there is a fixed probability $\left(\mu^{b}\right)$ in each period from $t=2$ to $t=9$, that the shock reverts to steady state in the following period.

We consider two scenarios that increase the agents beliefs about the duration at the ELB by one period: in the first, the Odyssean forward guidance, we impose the following rule:

$$
i_{t}= \begin{cases}0 & \text { for } t<\tau+1 \\ \bar{r}+\phi_{\pi} \pi_{t}+\phi_{y} \hat{Y}_{t} & \text { otherwise }\end{cases}
$$

The central bank announces to keep the interest rate low for an additional period, i.e. one more quarter than prescribed under the standard Taylor rule (TTR); this is an expansionary policy.

In the second scenario - where we implement Delphic forward guidance - we adjust the agents beliefs about the reversal probability $\left(\mu^{b}\right)$ to obtain the same increase of one period of the expected duration of the ELB. In order to obtain a longer duration, $\mu^{b}$ has to increase. This is a more contractionary shock than before. The two experiments are meant to separately study the effects of policy (Odyssean) and the effect of beliefs about fundamentals of the economy (Delphic).

Results are shown in Figure 7, the benchmark calibration is the same as before. The Odyssian forward guidance results in a increase in output, cutting the output contraction almost by a half. Meanwhile, the Delphic forward guidance leads to a sharp output contraction.

This experiment highlight the critical role of beliefs in the model. It also illustrates that the toolkit allows for the possibility of shifting beliefs without a change in fundamentals, which remain pinned down by the deterministic path for the natural rate of interest.

\subsection{Robustness Checks}

In the previous Sections we explored the performance of our novel policy rules, and we found that they improve upon several alternatives documented in the literature, such as PLT and NDGPT. We did so in an environment in which inflation on impact was slightly below steady state under a Taylor rule (-0.5 percent). This reflects what the U.S. economy experienced during the Great Recession of 2008.

We repeat the experiment with different parametrisations of the natural rate and cost push shock to have lower ( 0 percent) or higher (-2 percent) deflation on impact under TTR. Our results are robust to both scenarios - namely that HD-NGDPT and SDTR fare relatively well when compared to PLT and NGDPT. In particular, the welfare loss under HD-NGDPT (SDTR) is approximately 1.6 (1.2) times as large as in the optimal commitment policy. On the contrary, the welfare loss in both PLT and NGDPT is at least three times as large as in OCP. In Sections A.7.2 and A.7.3 in the Appendix we report the detailed performance assessment of our candidate rules, as well as plots for the impulse responses.

In the experiments so far the inflation response has been quite weak due to the presence of a cost push shock, perfectly correlated with the drop in the natural interest rate. An alternative theory for why inflation was so stable in the U.S. Great Recession points to price rigidity. We explore this avenue by 

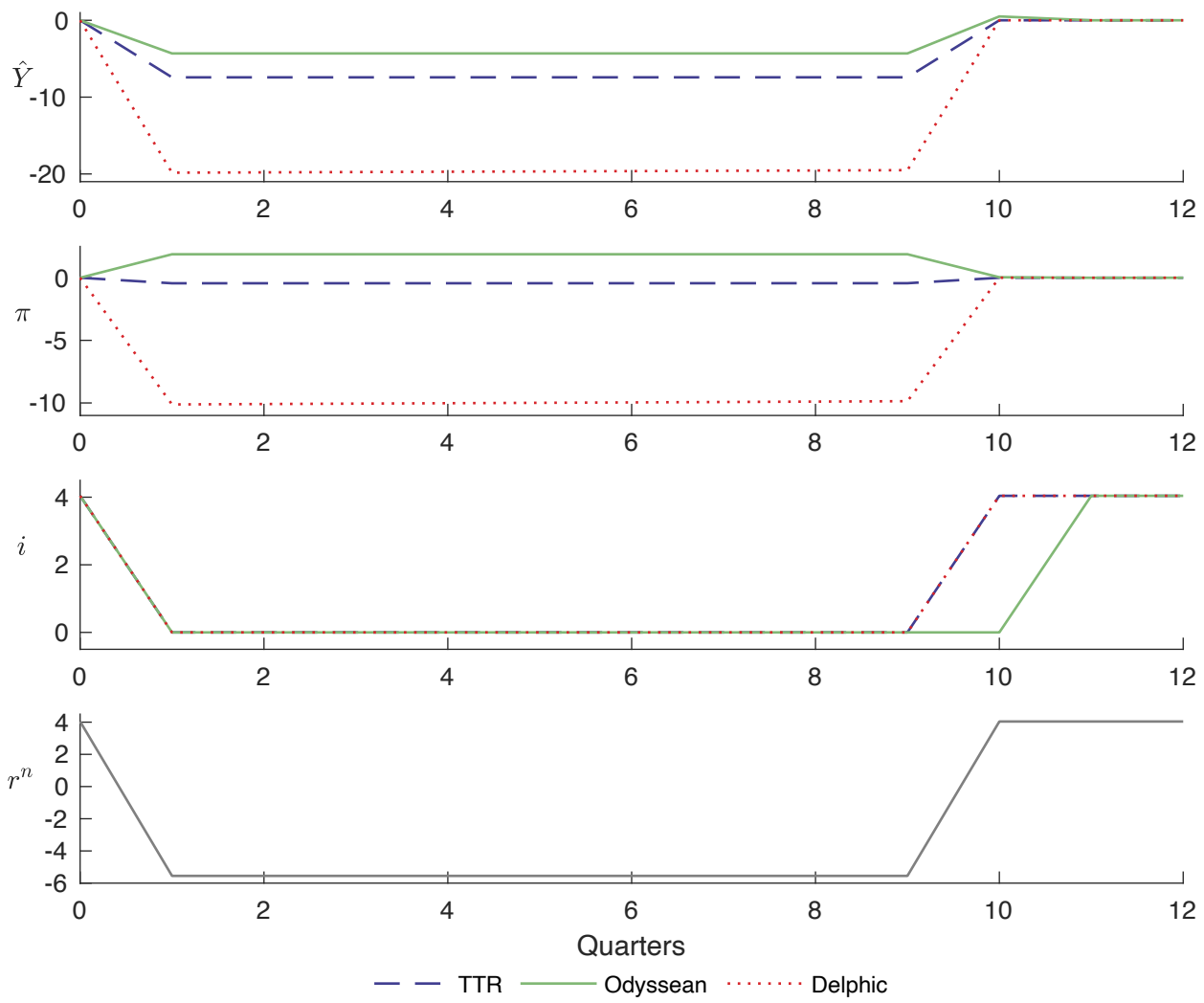

Figure 7: Odyssean vs. Delphic forward guidance (FG) experiment in simple two-equation NK model. Odyssean FG features commitment of central bank to one additional periods at ELB relative to Taylor rule (TTR). Delphic FG features lower transition probability of shock, $1-\mu^{b}$. Both scenarios have expected duration at ELB of 10 quarters, TTR has expected duration at ELB of 9 quarters. The coloured lines represent contingency 10 for output $(\hat{Y})$, inflation $(\pi)$, the nominal interest rate $(i)$ and the natural rate $\left(r^{n}\right)$. Calibration is the same as in Section 4.3 , achieving a drop in output in the initial period of $-7.5 \%$ and a fall in inflation to $-0.5 \%$ under discretion in response to a natural rate shock and a perfectly correlated cost push shock (TTR, blue solid line). Transition probability under Delphic FG is $\mu^{b}=0.09091$. The vertical axes for $\hat{Y}$ and $\pi$ report deviations from steady state, in percentage points (annualised figures). The vertical axis for $i$ and $r^{n}$ report annualised percentage points. 
repeating the exercise with no cost push shock, but with a degree of price rigidity such that, under TTR, inflation again drops to -0.5 percent on impact. We refer the reader to the Appendix (Section A.7.4) for welfare analysis and dynamic responses. Our two rules remain very good compared to the optimal policy commitment. On the other hand, strategies that were comparable to ours, ATR and SUP, now tend to fare significantly worse than OCP.

The last robustness check we perform involves the policy parameters: we choose them to maximise welfare according to Equation (25). ${ }^{30}$ The results are in Table A.8 in the Appendix (Section A.7.5); optimal parameters are reported in Table A.2. In this setting, only ATR and SUP - rules that display welfare losses comparable to ours - improve slightly in terms of welfare. All other optimised policies are virtually unchanged.

\section{Medium-Scale DSGE Model}

The results discussed so far were derived under a simple two-equation NK model. In this Section we show that the findings generalise to a medium-scale DSGE model and they are not an artefact of the simple structure of the baseline exercise. Rules that imply substantial make-up behaviour or feature inertia in the path of interest rates show the best outcome. Our two proposed policies, HD-NGDPT and SDTR, outperform all alternative candidates by implying substantial stimulus compared to a simple Taylor rule. As before, a price level target and nominal GDP target do not perform as well in an environment with a relatively stable prices. This Section also serves to illustrate how our toolkit can easily handle medium-scale models.

For this exercise, we implement the FRBNY DSGE as outlined in Del Negro, Giannoni and Patterson (2013). We treat the model as a reasonable description of the U.S. economy and simulate the Great Recession. In all our Figures, we plot the data against our simulations. Figure 8 shows the pre-crisis trend and the actual path for the U.S. nominal GDP and price level. We calibrate the model to match a similar decline of both variables as observed in the data. For the calibration, we use the policy rule proposed and estimated in Del Negro, Giannoni and Patterson (2013) as the one prevailing in the data-generating process (Equation A.7). ${ }^{31}$ This gives us the ideal testing grounds for the reaction functions introduced in the previous section. ${ }^{32}$

As an illustration, we assume that the shock that gave rise to the Great Recession reverts back to steady state right around the time the Federal Reserve started increasing interest rate in 2015. It is clearly an exaggeration to assume that the shock fully reverts back to it steady state at that time. We are willing to contemplate this scenario because it makes the thought experiment straightforward to interpret and comparable to our previous simulations.

Figure 9 compares the FRBNY policy rule with the four targeting rules, as well as with the data. We see that PLT and NGDPT do not improve significantly upon the FRBNY Rule, which is consistent with our experiment in the simple model. The reason as before is that the small drop in the price level does not generate strong enough of a commitment to low future rates. The FRBNY Rule implies 28 quarters at the ELB, as observed in the data. Relative to this, PLT and NGDPT only command five additional quarters at the lower bound after the shock reverts to the steady state. This is in stark contrast to our newly

\footnotetext{
${ }^{30}$ Targeting rules are not re-parametrised.

${ }^{31}$ In a medium-scale model like the FRBNY DSGE featuring many state variables, optimal commitment is cumbersome to derive. We therefore take the FRBNY policy as our baseline.

${ }^{32}$ Section A.5 in the Appendix contains details on the model and its calibration.
} 


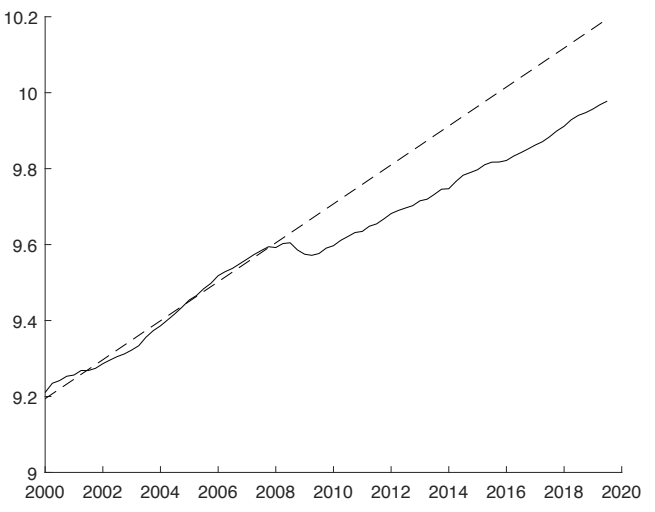

(a) Gross Domestic Product

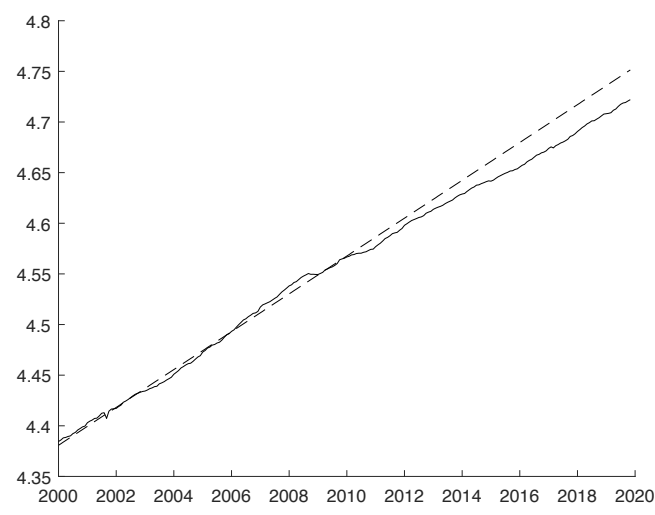

(b) Core Personal Consumption Expenditures

Figure 8: U.S. Gross Domestic Product (in Billions of Dollars) and Personal Consumption Expenditures ex. Food and Energy (Chain-Type Price Index, 2012=100). All series are in log-points and seasonally adjusted. The dashed line represents a linear trend estimated in the pre-Great Recession period (2000-Q1 to 2007-Q2). Data from the U.S. Bureau of Economic Analysis. For details on the data source see Footnote 39.

proposed rules: HD-NGDPT (SDTR) implies 16 (15) additional quarters at the ELB relative to the baseline, postponing the lift-off from zero well into the year 2019. This aggressive policy improves outcomes considerably: while output drops to -8.5 percent under the FRBNY Rule, and still to -6.3 percent (-6.0 percent) under PLT (NGDPT), the maximum drop in output under HD-NGDPT (SDTR) is -3.6 percent (-3.1 percent). In addition, we should note that output hits its trough early, and recovers thereafter. This improvement is achieved at the expense of a modest overshoot of inflation relative to the other rules.

We can assess the costs in term of output loss associated with the Federal Reserve's inability to flatten the path of the expected Federal Funds Rate in the early stages of the U.S. Great Recession. To this end, we compare the realised output loss implied by the model to trend output. For the time period 2007-Q3 to 2020-Q1 the FRBNY Rule implies an average annualised output gap of -5.07 percent, see Column (8) in Table 3. Our proposed rules reduce this number considerably: -0.34 for SDTR and -1.01 for HD-NGDPT. This means that the cumulative output gap since the Great Recession would have been almost closed by the first quarter of 2020 had the Federal Reserve implemented the SDTR policy rule. We also report the model-implied price level in 2020-Q1, see Column (9) of Table 3. Under the FRBNY Rule, the price level is still 3.5 percent below trend in 2020-Q1, while HD-NGDPT closes the price level gap (0.4 percent above target) and SDTR overcompensates (4.2 percent above target). While a price level target (PLT) closes the price level gap by 2020-Q1, it does not provide enough stimulus, and implies a rather large average annualised output gap of -3.74 percent.

Notably, we calibrate our model such that we exactly hit the relatively low expected duration of the ELB binding for four quarters at the early stages of the Great Recession, as found in surveys of professional forecasters. This is one benefit of the stochastic structure of the toolkit: we can simultaneously target moments of output loss and expectations about the duration of the ELB episode.

Our analysis suggests that had the Federal Reserve been able to credibly announce and implement HDNGDPT or SDTR, the path of the Federal Funds Rate expected by market participants would have been considerably flatter (compare to Figure A.20a in the Appendix). The expected duration at the ELB would have been about three times higher (12.9 and 13.4 quarters for HD-NGDPT and SDTR, respectively). ${ }^{33}$

\footnotetext{
${ }^{33}$ These numbers are different than the ones reported in Column 2 in Table 3 because in this section we condition on having reached the ELB. This makes the numbers comparable to the survey forecast of four quarters at the ELB. In Table 3 we report the unconditional expectation, i.e. from the point in time when the shock hits. Both metrics can differ because of the presence of regime
} 

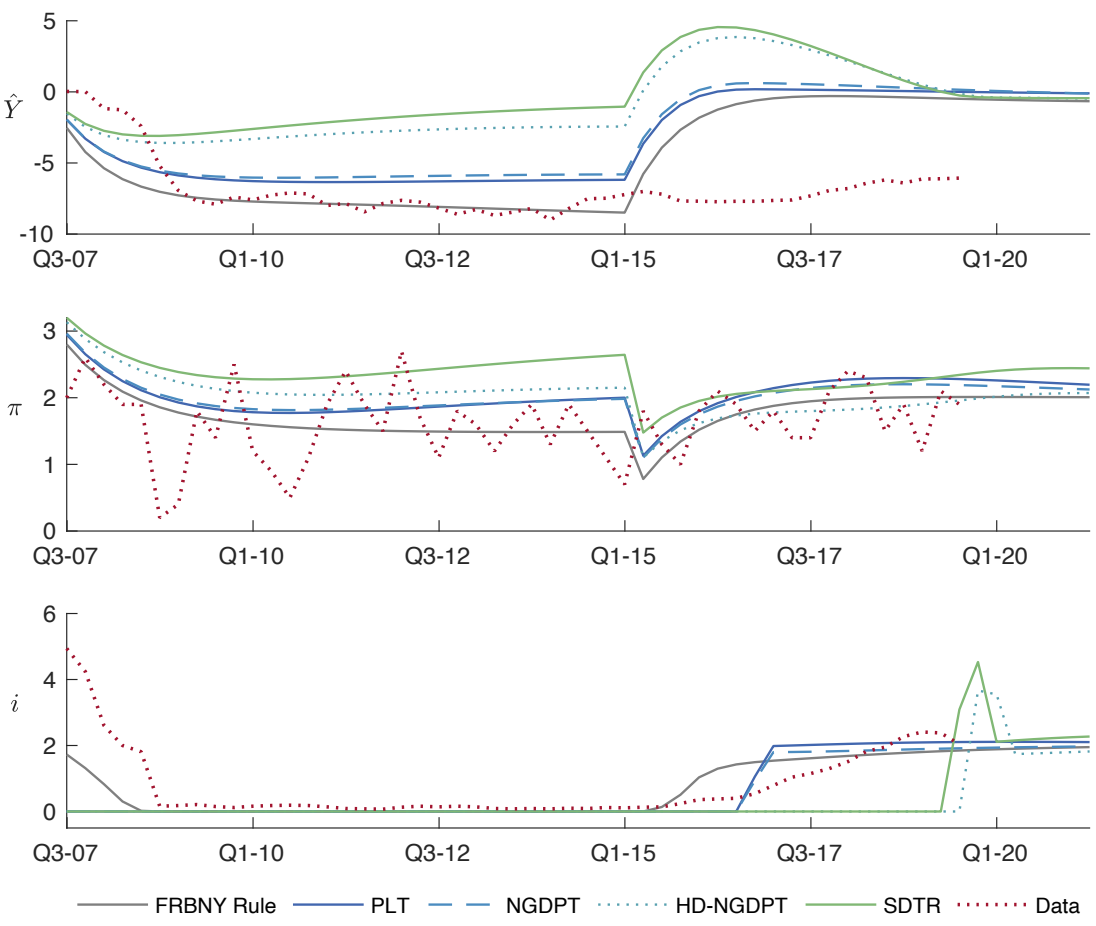

(a) Paths for output $(\hat{Y})$, inflation $(\pi)$ and nominal interest rate $(i)$
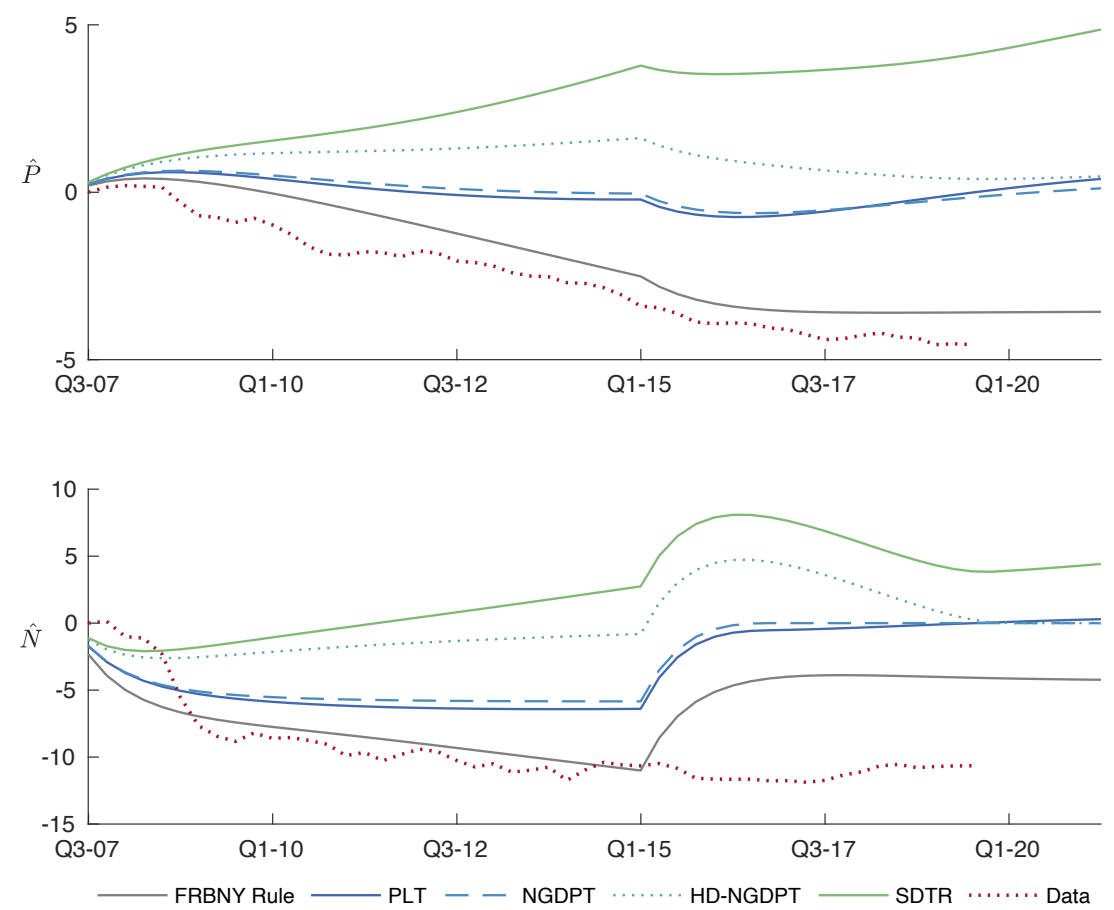

(b) Paths for price level $(\hat{P})$, nominal output $(\hat{N})$

Figure 9: Dynamic response to a preference shock and a correlated cost push shock in FRBNY model, under different policy rules. Dotted red line is data. The two-state Markov shocks switch to low state in Q4-07 and revert to the absorbing state after 32 quarters (32nd contingency). The vertical axes for $\hat{Y}$ and $\hat{N}$ report deviations from detrended steady state, in percentage points (annualised figures). The vertical axes for $\pi$ and the $i$ report annualised percentage points. The vertical axis for $\hat{P}$ reports percent deviations from its trend. The horizontal axis shows quarter and calendar year. See Section A.3 for details on data and Section A.5.2 for calibration. The list of acronyms is detailed in Table 1. 
This change is solely due to a difference in policy, as the fundamental shock to the economy is held constant.

Table 3, Figures 10 and A.17 show the results for the full set of reaction functions. ${ }^{34}$ Comparing the welfare loss across rules, we see that HD-NGDPT and SDTR outperform all others. Our proposals generate a loss that is only a third of the one under the FRBNY Rule, since they imply substantial additional stimulus. Indeed, the expected duration at the ELB (Column 2 in Table 3) is much longer than any alternative proposal. Of the remaining policies, ATR and SUP again show good performance and come the closest to our two candidate rules. Appendix A.6.2 discusses the case of the ELB constraint not being imposed. Our two proposed rules are again among the best performing ones.
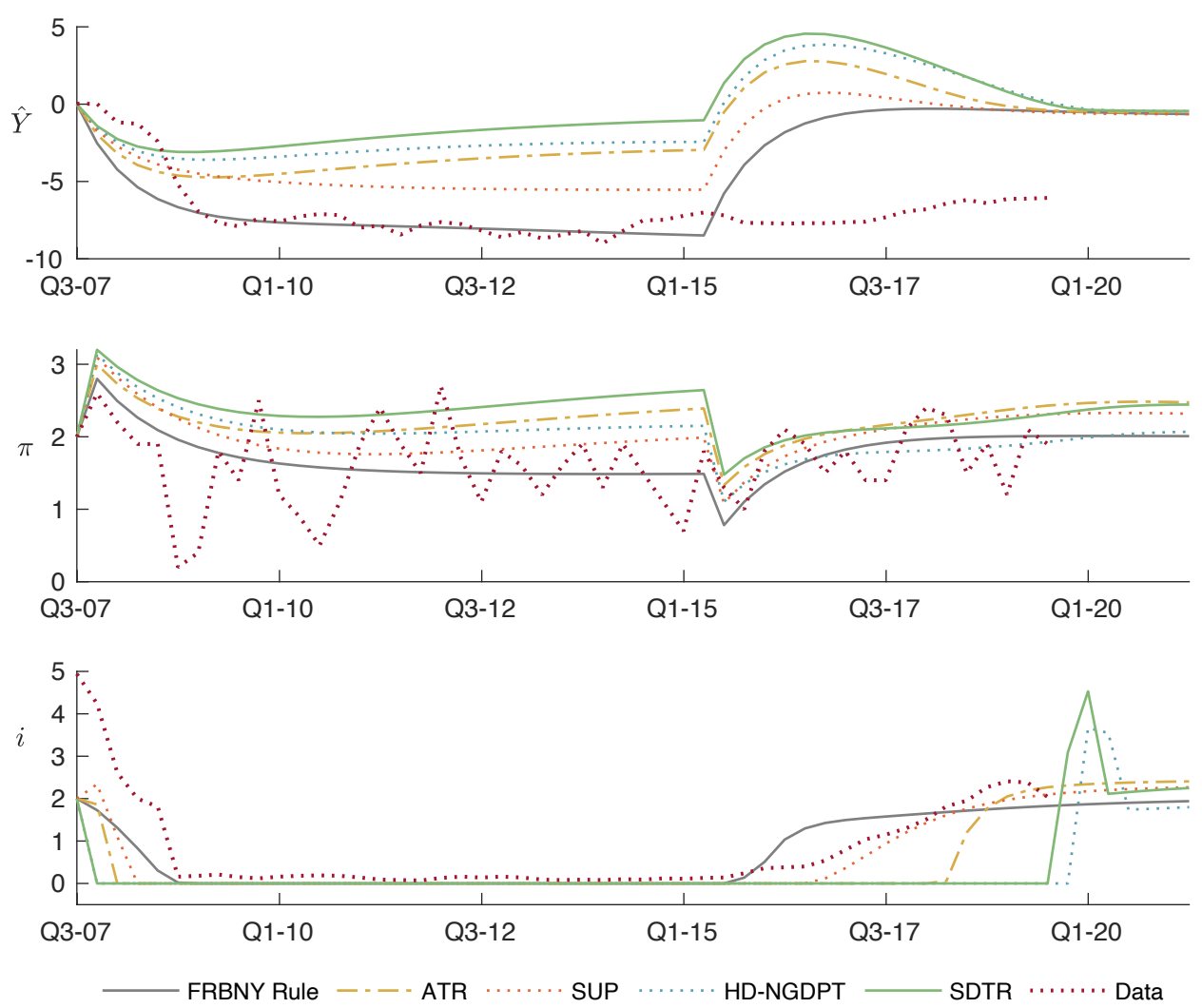

Figure 10: Dynamic response to a preference shock and a correlated cost push shock in FRBNY model, under baseline policy rules. Coloured lines show paths for output $\left(\hat{Y}_{t}\right)$, inflation $(\pi)$, the nominal interest rate $(i)$, and nominal $\operatorname{GDP}(\hat{N})$. Dotted red line is data. The two-state Markov shocks switch to low state in Q4-07 and revert to the absorbing state after 32 quarters (32nd contingency). The vertical axes for $\hat{Y}_{t}$ and $\hat{N}$ report deviations from detrended steady state, in percentage points (annualised figures). The vertical axes for $\pi$ and the $i$ report annualised percentage points. The horizontal axis shows quarter and calendar year. See Section A.3 for details on data and Section A.5.2 for calibration. The list of acronyms is detailed in Table 1. FRBNY Rule refers to Equation (A.7).

0

${ }^{34}$ Appendix A.7.6 shows impulse response functions and additional variables for all rules. 


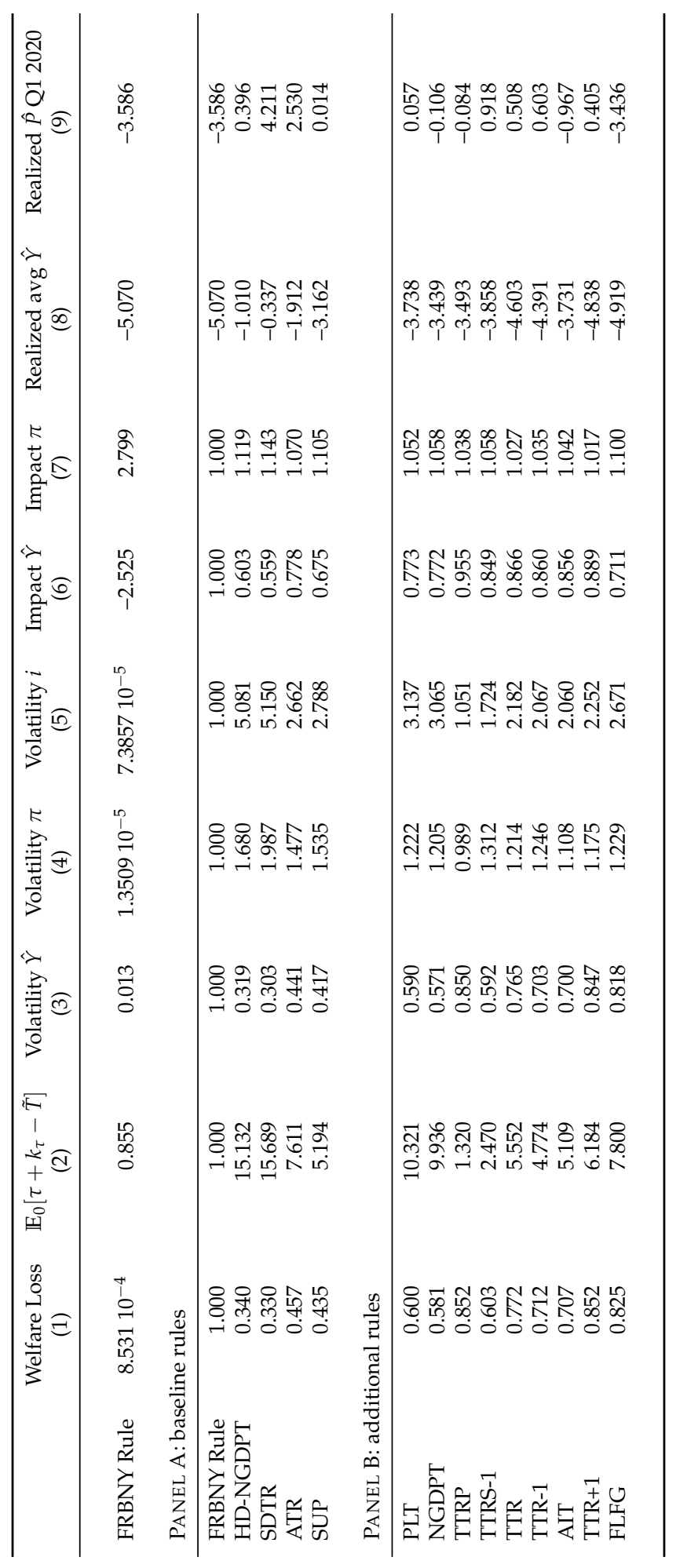

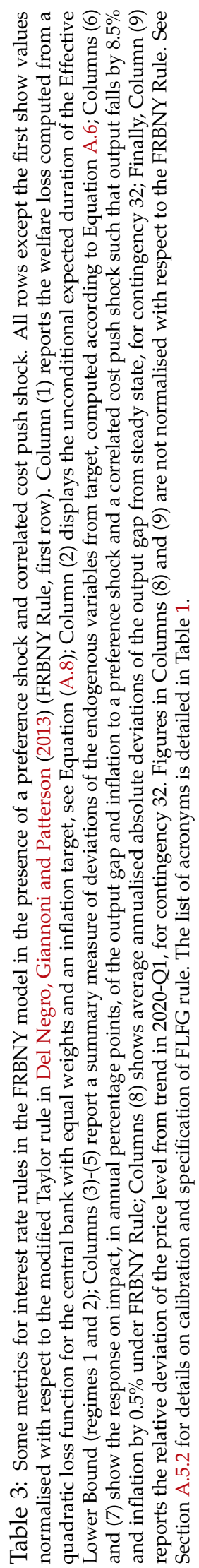




\section{Conclusions}

We provide a toolkit to solve DSGE models that involve occasionally binding constraints. The solution method generalises that of Eggertsson and Woodford (2003) and exploits the properties of a two-state Markov process for the exogenous disturbances. The toolkit performs well even in the presence of a large number of state variables and features a tractable stochastic structure. This modelling assumption is particularly relevant in the analysis of macroeconomic problems where uncertainty is important, as in the case of forward guidance.

We use the toolkit to study the performance of policy rules in economies that experience the ELB. Our two newly proposed strategies, a History-Dependent Nominal GDP Target and a Symmetric Dual-Objective Target, consistently outperform most rules documented in the literature, especially reaction functions based on price-level or nominal-GDP targeting. We show that the latter two lack sufficient stimulus during economic downturns characterised by small drop in the price level, as experienced in the recent U.S. Great Recession episode. In addition, our rules are easy to communicate to the public in the form of a state-contingent strategy, and are robust to different crisis scenarios.

Finally, we evaluate their performance in a medium-scale DSGE model for the U.S. economy. Our analysis suggests that our make-up strategies - if credibly conveyed to market participants by the Federal Reserve would have resulted in a much longer expected duration at the ELB after the Great Recession, and in an 80-percent reduction in lost output. Similarly, the Fed's monetary policy strategy outlined in the recently revised Consensus Statement (Powell 2020) would have reduced the output contraction by more than a quarter. 


\section{References}

Adam, Klaus, and Roberto M. Billi. 2006. "Optimal Monetary Policy under Commitment with a Zero Bound on Nominal Interest Rates." Journal of Money, Credit and Banking, 38(7): 1877-1905.

Adjemian, Stéphane, and Michel Juillard. 2011. "Accuracy of the Extended Path Simulation Method in a New Keynesian Model with Zero Lower Bound on the Nominal Interest Rate." Unpublished manuscript.

Adjemian, Stéphane, and Michel Juillard. 2013. “Stochastic Extended Path Approach." Unpublished manuscript.

Aspen Publishers. 2008-12. "Blue Chip Financial Forecasts." Various issues from 2008-12.

Benigno, Pierpaolo, Gauti B. Eggertsson, and Federica Romei. 2020. “Dynamic Debt Deleveraging and Optimal Monetary Policy." American Economic Journal: Macroeconomics.

Blanchard, Olivier Jean, and Charles M. Kahn. 1980. “The Solution of Linear Difference Models under Rational Expectations." Econometrica, 48(5): 1305-1311.

Board of Governors of the Federal Reserve System. 2019. "Projections materials released with December 10-11, 2019 FOMC Meeting Statement."

Boneva, Lena Mareen, R. Anton Braun, and Yuichiro Waki. 2016. "Some Unpleasant Properties of Loglinearized Solutions when the Nominal Rate is Zero." Journal of Monetary Economics, 84: 216-232.

Burstein, Ariel, and Christian Hellwig. 2008. "Welfare Costs of Inflation in a Menu Cost Model." American Economic Review, 98(2): 438-43.

Campbell, Jeffrey, Charles L. Evans, Jonas Fisher, and Alejandro Justiniano. 2012. "Macroeconomic Effects of Federal Reserve Forward Guidance." Brookings Papers on Economic Activity, 43(1): 1-80.

Christiano, Lawrence J., Martin S. Eichenbaum, and Mathias Trabandt. 2015. “Understanding the Great Recession." American Economic Journal: Macroeconomics, 7(1): 110-67.

Del Negro, Marco, Marc Giannoni, and Christina Patterson. 2013. “The Forward Guidance Puzzle." Federal Reserve Bank of New York Staff Reports 574. October 2012. Revised May 2013.

Del Negro, Marco, Stefano Eusepi, Marc Giannoni, Argia M. Sbordone, Andrea Tambalotti, Matthew Cocci, Raiden B. Hasegawa, and M. Henry Linder. 2013. “The FRBNY DSGE Model." Federal Reserve Bank of New York Staff Reports 647.

Denes, Matthew, Gauti B Eggertsson, and Sophia Gilbukh. 2013. “Deficits, public debt dynamics and tax and spending multipliers." The Economic Journal, 123(566): F133-F163.

Eggertsson, Gauti B., and Masayuki Inui. 2020. “The Dual Mandate Revisited.” Unpublished manuscript.

Eggertsson, Gauti B., and Michael Woodford. 2003. "The Zero Bound on Interest Rates and Optimal Monetary Policy." Brookings Papers on Economic Activity, 2003(1): 139-233.

Eggertsson, Gauti B., and Paul Krugman. 2012. “Debt, Deleveraging, and the Liquidity Trap: A FisherMinsky-Koo Approach." The Quarterly Journal of Economics, 127(3): 1469-1513.

Eggertsson, Gauti B., and Sanjay R. Singh. 2019. “Log-linear Approximation Versus an Exact Solution at the ZLB in the New Keynesian Model." Journal of Economic Dynamics and Control, 105: 21-43. 
Eggertsson, Gauti B., and Sergei K. Egiev. 2020. "Fundamental Driven Liquidity Traps: A Unified Theory of the Great Depression and the Great Recession." Working paper.

Fair, Ray C., and John B. Taylor. 1983. "Solution and Maximum Likelihood Estimation of Dynamic Nonlinear Rational Expectations Models." Econometrica, 51(4): 1169-1185.

Fernández-Villaverde, Jesús, Juan F. Rubio-Ramírez, and Frank Schorfheide. 2016. "Chapter 9 - Solution and Estimation Methods for DSGE Models." In . Vol. 2 of Handbook of Macroeconomics, 527-724. Elsevier.

FRED. 2020. "Federal Reserve Economic Data - Federal Reserve Bank of St. Louis."

Guerrieri, Luca, and Matteo Iacoviello. 2015. “OccBin: A Toolkit for Solving Dynamic Models with Occasionally Binding Constraints Easily." Journal of Monetary Economics, 70: 22-38.

Gust, Christopher, Edward Herbst, David López-Salido, and Matthew E Smith. 2017. "The empirical implications of the interest-rate lower bound." American Economic Review, 107(7): 1971-2006.

Hatzius, Jan, and Sven Jari Stehn. 2011. “The Case for a Nominal GDP Level Target.” Goldman Sachs US Economics Analyst, 11: 41.

Holden, Tom. 2016. "Computation of Solutions to Dynamic Models with Occasionally Binding Constraints." Working paper.

Holden, Tom, and Michael Paetz. 2012. "Efficient Simulation of DSGE Models with Inequality Constraints." University of Surrey, School of Economics Discussion Papers.

Judd, Kenneth L. 1998. Numerical Methods in Economics. Vol. 1 of MIT Press Books, The MIT Press.

Jung, Taehun, Yuki Teranishi, and Tsutomu Watanabe. 2005. “Optimal Monetary Policy at the ZeroInterest-Rate Bound." Journal of Money, Credit and Banking, 37(5): 813-835.

Kiley, Michael, and John Roberts. 2017. "Monetary Policy in a Low Interest Rate World." Brookings Papers on Economic Activity, 48(1 (Spring)): 317-396.

Kim, Sunghyun Henry, Robert Kollmann, and Jinill Kim. 2010. "Solving the Incomplete Market Model with Aggregate Uncertainty using a Perturbation Method." Journal of Economic Dynamics and Control, 34(1): $50-58$.

King, Robert G, and Mark W Watson. 1998. "The Solution of Singular Linear Difference Systems under Rational Expectations." International Economic Review, 1015-1026.

Laséen, Stefan, and Lars E.O. Svensson. 2011. "Anticipated Alternative Policy Rate Paths in Policy Simulations." Internation Journal of Central Banking.

Maliar, Lilia, and Serguei Maliar. 2015. "Merging Simulation and Projection Approaches to Solve High-dimensional Problems with an Application to a New Keynesian Model." Quantitative Economics, 6(1): $1-47$.

Mertens, Thomas M., and John C. Williams. 2019a. "Monetary Policy Frameworks and the Effective Lower Bound on Interest Rates." 109: 427-432.

Mertens, Thomas M., and John C. Williams. 2019b. "Tying down the anchor: monetary policy rules and the lower bound on interest rates." Federal Reserve Bank of New York Staff Reports 887. 
Miao, Jianjun, and Phuong V. Ngo. 2019. “Does Calvo Meet Rotemberg at the Zero Lower Bound?" Macroeconomic Dynamics, 1-22.

Nakamura, Emi, and Jón Steinsson. 2018. “High-Frequency Identification of Monetary Non-Neutrality: The Information Effect." The Quarterly Journal of Economics, 133(3): 1283-1330.

Nakamura, Emi, Jón Steinsson, Patrick Sun, and Daniel Villar. 2018. “The Elusive Costs of Inflation: Price Dispersion during the U.S. Great Inflation." The Quarterly Journal of Economics, 133(4): 1933-1980.

Nakov, Anton. 2008. "Optimal and Simple Monetary Policy Rules with Zero Floor on the Nominal Interest Rate." International Journal of Central Banking, 4(2): 73-127.

Powell, Jerome. 2020. “New Economic Challenges And The Fed's Monetary Policy Review at "Navigating The Decade Ahead: Implications For Monetary Policy"." An Economic Policy Symposium Sponsored By The Federal Reserve Bank Of Kansas City, Jackson Hole.

Preston, Bruce, and Mauro Roca. 2007. “Incomplete Markets, Heterogeneity and Macroeconomic Dynamics." NBER Working Paper No. 13260.

Reifschneider, David, and David Wilcox. 2019. "Average Inflation Targeting Would Be a Weak Tool for the Fed to Deal with Recession and Chronic Low Inflation." Peterson Institute for International Economics Policy Briefs PB19-16.

Reifschneider, David, and John C Williams. 2000. “Three Lessons for Monetary Policy in a Low-inflation Era." Journal of Money, Credit and Banking, 936-966.

Rotemberg, Julio J, and Michael Woodford. 1997. “An optimization-based econometric framework for the evaluation of monetary policy." NBER macroeconomics annual, 12: 297-346.

Rotemberg, Julio J., and Michael Woodford. 1999. "Interest Rate Rules in an Estimated Sticky Price Model." Monetary Policy Rules, 57-126. University of Chicago Press.

Schmitt-Grohé, Stephanie, and Martín Uribe. 2009. “Liquidity Traps with Global Taylor Rules." International Journal of Economic Theory, 5(1): 85-106.

Sumner, Scott. 2012. “The Case for Nominal GDP Targeting." Mercatus Research.

Taylor, John B., and John C. Williams. 2010. "Simple and Robust Rules for Monetary Policy." In Handbook of Monetary Economics. Vol. 3 of Handbook of Monetary Economics, , ed. Benjamin M. Friedman and Michael Woodford, Chapter 15, 829-859. Elsevier.

Wolman, Alexander L. 2005. "Real Implications of the Zero Bound on Nominal Interest Rates." Journal of Money, Credit and Banking, 37(2): 273-296.

Woodford, Michael. 2003. Interest and Prices: Foundations of a Theory of Monetary Policy. Princeton University Press.

Woodford, Michael. 2012. "Methods of Policy Accommodation at the Interest-rate Lower Bound." Proceedings - Economic Policy Symposium - Jackson Hole, 185-288. 